\title{
Forced periodic operations of a chemical reactor for methanol synthesis - the search for the best scenario based on Nonlinear Frequency Response Method. Part I Single input modulations
}

Daliborka Nikolić $^{\mathrm{a}, *}$, Carsten Seidel ${ }^{\mathrm{b}}$, Matthias Felischak ${ }^{\mathrm{c}}$, Tamara Miličić ${ }^{\mathrm{d}}$, Achim Kienle ${ }^{\mathrm{b}, \mathrm{c}}$, Andreas Seidel-Morgenstern ${ }^{\mathrm{b}, \mathrm{c}}$, Menka Petkovska $^{\mathrm{d}}$

${ }^{a}$ University of Belgrade, Institute of Chemistry, Technology and Metallurgy, Njegoševa 12, 11000 Belgrade, Serbia

${ }^{\mathrm{b}}$ Otto-von-Guericke University, Universitätsplatz 2, 39106 Magdeburg, Germany

${ }^{\mathrm{c}}$ Max-Planck Institute for Dynamics of Complex Technical Systems, Sandtorstrasse 1, 39106

Magdeburg, Germany

${ }^{\mathrm{d}}$ University of Belgrade, Faculty of Technology and Metallurgy, Department of Chemical Engineering, Karnegijeva 4, 11000 Belgrade, Serbia

\begin{abstract}
In this two-part paper a comprehensive study of the potential to improve performance criteria of a methanol synthesis reactor through forced periodical operations is presented. The study uses the Nonlinear Frequency Response method, a powerful analytical and approximate tool which gives an answer whether and under which conditions certain periodic operation would lead to improvement of process performance. To demonstrate the method, isothermal and isobaric methanol synthesis in a lab-scale CSTR is considered. In Part I, the analysis is performed for single input modulations. Partial pressures of each reactant in the feed stream and the total inlet volumetric flow-rate are considered as possible modulated inputs. The results show that modulations of single inputs essentially do not provide potential for significant improvements. In Part II, the study will be extended to analysis of periodic operations with simultaneous modulations of two inputs and conditions offering significant performance enhancements will be identified.
\end{abstract}

Keywords: Forced periodic operations, Methanol synthesis, Nonlinear frequency response, Process improvement, Single input modulations

*Corresponding author. Tel.: +381 113640 221. E-mail address: daliborkan @ihtm.bg.ac.rs 


\section{Introduction}

Operating processes in forced periodic mode is one way of Process Intensification (PI), which represents a set of innovative principles in process or equipment design leading to significant process improvements (Van Gerven and Stankiewicz, 2009). The term forced periodic operation refers to a case when one or more inputs of a system are periodically modulated around their corresponding steady-state value(s) (Petkovska and Seidel-Morgenstern, 2013). In chemical engineering, the standard way to design and operate continuous processes is based on the optimal steady-state design and a control system which keeps all outputs as close as possible to theirs optimal steady-state values. Nevertheless, it is a known fact that perturbing the system periodically can sometimes result in better performance than the optimal steady-state operation (Silveston and Hudgins, 2013). Forced periodic operations of chemical reactors have been of interest for many research groups worldwide, involved in numerous theoretical, numerical or experimental studies (Armstrong and Teixeira, 2020; Bailey 1973; Douglas and Rippin 1966; Douglas 1967; Douglas 1972; Renken 1972; Schadlich et al. 1983; Silveston 1987; 1998; Silveston and Hudgins, 2013; Sterman and Ydstie 1990a, 1990b, 1991; Chen et al., 1994). These studies showed that the time-average indicators of chemical reactor performance, such as conversion, selectivity, production rates, productivity, could be improved by implementing forced periodic operations.

Although the physical reasons can be different, it could be said that the process improvement owing to forced periodic operations is always a consequence of process nonlinearity (Petkovska and Seidel-Morgenstern, 2013). Also, it is important to know that the resulting performances could be improved, deteriorated or unchanged, in comparison to the steady-state performance (Douglas and Rippin, 1966). Considering that there are many ways to apply forced periodic operations, e.g.: different inputs which can be modulated, different shapes of the modulated input(s), different values of the forcing parameters (amplitude(s), frequency, phase difference, etc.), it is a challenging task to find the mode which would lead to the highest improvement (Parulekar, 2003; Silveston et al., 1995). It is therefore of economic importance to carry out theoretical studies for assessing the effects of forced periodic operations of chemical processes, before any experimental studies (Chen et al., 1994). In our previous work (Marković et al, 2008; Nikolić, 2016; Petkovska and Seidel-Morgenstern, 2013; Petkovska et al., 2018) we introduced the Nonlinear Frequency Response (NFR) method as a reliable analytical tool for evaluating possible improvements and finding the best forcing parameters (Nikolić, 2016; Živković et al., 2020b). 
The Nonlinear Frequency Response (NFR) method is based on the analysis of the frequency response of weakly nonlinear systems (Nikolić, 2016; Petkovska and Seidel-Morgenstern, 2013; Petkovska et al., 2018). It is a general, mathematically based theoretical and approximate method which answers the following questions (Nikolić, 2016; Petkovska and Seidel-Morgenstern, 2013; Petkovska et al., 2018):

- Can the process performance be improved by periodic input modulations or not?

- Which input(s) should be periodically modulated in order to improve the process performance?

- Which forcing parameters (amplitude(s) and frequency of the input modulations, as well as the phase difference in the case of simultaneous modulation of two inputs) should be used?

- What would be the extent of the possible improvement?

Until now, the NFR method has been applied for studying forced periodic operations of several different reactor systems. Simple irreversible $n^{\text {th }}$ order reactions were considered in continuous stirred tank reactor (CSTR) (Marković et al., 2008; Nikolić-Paunić and Petkovska, 2013; Nikolić and Petkovska, 2016; Nikolić et al., 2014a, 2014b, 2015; Nikolić, 2016; Nikolić et al., 2016a, 2016b, 2020; Petkovska et al., 2010;), plug flow reactor (PFR) and dispersed flow tubular reactor (DFTR) (Marković et al., 2008). Different thermal regimes were studied: isothermal (Marković et al., 2008; Nikolić-Paunić and Petkovska, 2013; Nikolić and Petkovska, 2016; Petkovska et al., 2010), general non-isothermal (Nikolić-Paunić and Petkovska, 2013; Nikolić et al., 2014a, 2014b, 2015, 2016) and adiabatic (Nikolić, 2016; Nikolić et al., 2016b; Nikolić et al., 2020). Single input modulation of different input shapes: general (Nikolić and Petkovska, 2016; Nikolić et al., 2020), sinusoidal (Marković et al., 2008; Nikolić-Paunić and Petkovska, 2013; Nikolić and Petkovska, 2016; Nikolić et al., 2014a, 2014b, 2015; Nikolić, 2016; Nikolić et al., 2016a, 2016b; Petkovska et al., 2010;), square-wave (Nikolić and Petkovska, 2016; Nikolić et al., 2020), for inlet reactant concentration (Marković et al., 2008; Nikolić-Paunić and Petkovska, 2013; Nikolić and Petkovska, 2016; Nikolić et al., 2014a, 2014b, 2015; Nikolić, 2016; Petkovska and SeidelMorgenstern, 2013; Petkovska et al., 2010;), flow-rate (Nikolić-Paunić and Petkovska, 2013; Nikolić, 2016; Nikolić et al., 2016a, 2016b), inlet temperature and temperature of the cooling/heating medium modulation (Nikolić et al., 2014b, 2015), as well as simultaneous modulation of two inputs (Nikolić-Paunić and Petkovska, 2013; Nikolić et al., 2015;2016a, 2016b, 2020; Nikolić, 2016) were considered. The NFR method was also used for analysis of forced periodic operation for Sabatier reaction (Currie et al., 2018). 
Recently, the results of NFR analysis of forced periodically operated adiabatic reactor in which hydrolysis of acetic anhydride occurs for simultaneous modulation of two inputs, inlet concentration and flow-rate (Nikolić, 2016; Nikolić et al., 2016b), have been experimentally confirmed (Felischak, 2020; Felischak et al., 2021).

Also recently, the NFR method was further advanced into the so-called computer-aided Nonlinear Frequency Response (cNFR) method, by developing a user friendly software application for implementing the NFR method, making its application much easier (Živković et al., 2020a). Another recent development was establishing and implementing a new methodology for optimizing forced periodic operations, combining the cNFR approach and multi-objective optimization the one step optimization (Živković et al., 2020b). The main advantage of this approach is that using the NFR approach leads to objective functions which are defined as algebraic expressions of all optimization parameters, which drastically shortens the needed computing time. Also, the optimization is performed in a single step, meaning that all optimization parameters: the steady state point around which the forced periodic operation should be performed and the forcing parameters (frequency, amplitudes and phase difference) are determined at the same time.

In this paper, the NFR method is used for analysing the potential of forced periodical operations of a chemical reactor in which the catalytic methanol synthesis from synthesis gas occurs. Methanol is an important basic chemical which is produced on large scale in chemical industry and used as starting material for production of paraffins, olefins and other organic chemicals, as well as fuel or fuel additives (Fiedler et al., 2000). The important fact is that methanol can be used as an energy carrier (Olah, 2004). Excess electrical energy from renewable resources (wind or solar) can be used to generate hydrogen which, combined with $\mathrm{CO}$ and/or $\mathrm{CO}_{2}$ (from biomass or agriculture waste streams) in the presence of a suitable catalyst, can be converted into methanol as a medium for chemical energy storage (Larsten and Sonderberg, 2013; Martin, 2016; Olah, 2005; Raeuchle et al., 2016; Seidel et al., 2018). However, methanol production for energy storage using renewable resources deals with unavoidable fluctuations in the supply of hydrogen, $\mathrm{CO}$ and/or $\mathrm{CO}_{2}$. In some cases, these fluctuations could lead to improvement of methanol production. Previous experimental investigations showed that significant improvement in methanol production could be achieved by forced periodic operations (Chanchlani et al., 1992, 1994; Silveston, 1987). Experimental results presented in (Chanchlani et al., 1992, 1994) showed that the improvement of about $35 \%$ increase of methanol production relative to steady state is possible (when $\mathrm{H}_{2}$ and $\mathrm{CO}_{2}$ in the feed stream are periodically modulated) for an 
isothermal packed bed reactor when $\mathrm{Cu} / \mathrm{ZnO}$ and $\mathrm{Cu} / \mathrm{ZnO} / \mathrm{Al}_{2} \mathrm{O}_{3}$ were used as catalyst at $225^{\circ} \mathrm{C}$ and $2.86 \mathrm{MPa}$.

In this two-part manuscript we use the NFR method to perform a systematic search for the best periodic process which would intensify the process of methanol synthesis. In Part I of this work, the NFR analysis is performed for cases of single input modulations. In Part II, the cases of simultaneous modulations of two inputs will be analysed.

\section{Nonlinear frequency response method for single input modulations}

By definition, frequency response is the quasi-stationary response of a stable system to a periodic (sinusoidal or co-sinusoidal) input modulation around its steady-state value (Douglas, 1972). Frequency response is obtained when the transient response becomes negligible (theoretically for infinite time). For linear systems, frequency response is a periodic function of the same shape and frequency as the input function, but with different amplitude, with a phase shift and the mean value which is equal to the steady-state one.

On the other hand, frequency response of a nonlinear system is a complex periodic function. For a weakly nonlinear system (Weiner and Spina, 1980), if the input $x$ is modulated in a cosinewave form, with amplitude $A$ and frequency $\omega$, around a steady-state value $x_{s}$ :

$x(t)=x_{\mathrm{s}}+A \cos (\omega t)$

after long enough (theoretically infinite) time, the output of the system would contain the basic harmonic $\left(y_{I}\right)$ which has the same frequency as the input modulation, a non-periodic (the socalled DC) component $\left(y_{\mathrm{DC}}\right)$ and an infinite number of higher harmonics $\left(y_{I I}, y_{I I I}, \ldots\right)$ (Douglas, 1972; Weiner and Spina, 1980):

$y(t)=y_{s}+y_{D C}+y_{I}+y_{I I}+y_{I I I}+\cdots=y_{s}+y_{D C}+B_{I} \cos \left(\omega t+\varphi_{I}\right)+B_{I I} \cos \left(2 \omega t+\varphi_{I I}\right)+$ $B_{I I I} \cos \left(3 \omega t+\varphi_{I I I}\right)+\cdots$

where $y(t)$ represents the output, $y_{s}$ its steady-state value, while $B_{i}$ and $\varphi_{i}$ are the amplitude and the phase shift of the $i$-th harmonic of the output, respectively.

One convenient approach of analysing the frequency response of weakly nonlinear systems is the concept of higher order frequency response functions (FRFs). This approach is based on Volterra series and the generalized Fourier transform (Nikolić, 2016; Petkovska and Seidel-Morgenstern, 2013; Petkovska et al., 2018;Weiner and Spina, 1980). Using this approach, the nonlinear model of a weakly nonlinear system can be replaced with a series of FRFs of different orders: $G_{\mathrm{y}, \mathrm{x}}^{(1)}\left(\omega_{1}\right), G_{\mathrm{y}, \mathrm{x}, \mathrm{x}}^{(2)}\left(\omega_{1}, \omega_{2}\right), \ldots, \underbrace{\left(\omega_{1}\right)}_{\mathrm{y}, \underbrace{(n), \ldots, \mathrm{x}}_{n}} \underbrace{\left.\omega_{1}, \ldots, \omega_{n}\right), \ldots}_{n}$ These FRFs are directly related with 
the DC component and different harmonics of the frequency response (Nikolić, 2016; Petkovska and Seidel-Morgenstern, 2013; Petkovska et al., 2018).

This method can be applied on weakly nonlinear, stable systems, without multiple steady-states, which can be represented with convergent Volterra series (Nikolić, 2016; Petkovska and SeidelMorgenstern, 2013; Živković et al., 2020a).

In order to evaluate a forced periodic operation around a steady-state point, only the timeaverage value of the periodic steady-state response is of interest. Using equation (2) it is easily concluded that the DC (non-periodic) component of the frequency response equals the difference between the time-average and the steady-state value of the output. Using the concept of higher order FRFs, the DC component can be written as the following infinite series (Weiner and Spina, 1980):

$y_{\mathrm{DC}}=2\left(\frac{A}{2}\right)^{2} G_{\mathrm{y}, \mathrm{x}, \mathrm{x}}^{(2)}(\omega,-\omega)+6\left(\frac{A}{2}\right)^{4} G_{\mathrm{y}, \mathrm{X}, \mathrm{X}, \mathrm{X}, \mathrm{x}}^{(4)}(\omega, \omega,-\omega,-\omega)+\cdots$

In equation (3) $G_{\mathrm{y}, \mathrm{x}, \mathrm{x}}^{(2)}(\omega,-\omega)$ is the asymmetrical second order FRF, $G_{\mathrm{y}, \mathrm{x}, \mathrm{x}, \mathrm{x}, \mathrm{x}}^{(4)}(\omega, \omega,-\omega,-\omega)$ the asymmetrical fourth order FRF, etc.

For weakly nonlinear systems, the significance of different terms in equation (3) decreases with the increase of the corresponding FRF order. As a consequence, the DC component can be approximated with its dominant term, which is proportional to the asymmetrical second order function and the square of the input amplitude (Marković et al., 2008):

$y_{\mathrm{DC}} \approx 2\left(\frac{A}{2}\right)^{2} G_{\mathrm{y}, \mathrm{x}, \mathrm{x}}^{(2)}(\omega,-\omega)$

Equation (4) is the foundation of the NFR method for evaluating periodic operations with one modulated input. The sign of $G_{\mathrm{y}, \mathrm{x}, \mathrm{x}}^{(2)}(\omega,-\omega)$ determines whether the periodic operation would be superior to the corresponding steady-state one, while its magnitude determines the possible improvement.

The FRFs of interest are derived starting from a nonlinear dynamic model of the investigated system. The derivation procedure of the FRFs is standard and it can be found in our previous publications (Marković et al., 2008; Nikolić-Paunić and Petkovska, 2013; Nikolić et al., 2014a, 2014b, 2015; Nikolić, 2016; Nikolić and Petkovska, 2016; Nikolić et al., 2016a, 2016b, 2020; Petkovska et al., 2010; Petkovska and Seidel-Morgenstern, 2013; Petkovska et al., 2018). 


\section{Methanol synthesis reaction.}

In this paper the focus is on the production of methanol from syngas (a mixture of $\mathrm{CO}, \mathrm{CO}_{2}$ and $\mathrm{H}_{2}$ ) using a commercial $\mathrm{Cu} / \mathrm{ZnO} / \mathrm{Al}_{2} \mathrm{O}_{3}$ catalyst. The overall reaction mechanism assumes the reactions of $\mathrm{CO}$ and $\mathrm{CO}_{2}$ hydrogenation:

$\mathrm{CO}+2 \mathrm{H}_{2} \rightleftarrows \mathrm{CH}_{3} \mathrm{OH}$

$\mathrm{CO}_{2}+3 \mathrm{H}_{2} \rightleftarrows \mathrm{CH}_{3} \mathrm{OH}+\mathrm{H}_{2} \mathrm{O}$

and the reverse water-gas shift reaction (RWGS):

$\mathrm{CO}_{2}+\mathrm{H}_{2} \rightleftarrows \mathrm{CO}+\mathrm{H}_{2} \mathrm{O}$

(see e.g. Graaf et al. (1988)).

\section{Kinetic model}

The NFR analysis presented in this work is based on a mathematical model of the reactor incorporating a reaction kinetic model of methanol synthesis presented in Seidel et al. (2018, 2020), which showed reasonable agreement with steady state and dynamic experimental data from the Ph.D. Thesis of Vollbrecht (2007). The model is based on a Langmuir-Hinshelwood mechanism which implies three main steps: adsorption of the reactants on the catalyst surface, reaction of the adsorbed species and desorption of the reaction products. Adsorption and desorption are assumed to be in equilibrium. Further, the model assumes three different active centres on the catalytic surface, i.e.

- $\quad$ oxidized surface centres $(\odot)$

- reduced surface centres $(*)$

- $\quad$ active surface centres for heterolytic decomposition of hydrogen $(\otimes)$.

The fraction of the reduced surface centres was denoted by $\phi$. Following Ovesen et al. (1997), changes in the catalyst morphology due to the oxidizing influence of $\mathrm{CO}_{2}$ and $\mathrm{H}_{2} \mathrm{O}$ and the reducing influence of $\mathrm{CO}$ and $\mathrm{H}_{2}$ were also taken into account and modelled with the following dynamic equation:

$\frac{d \phi}{d t}=k_{1}^{+}\left(y_{C O}\left(\phi_{\max }-\phi\right)-\frac{1}{K_{1}} y_{C_{2}} \phi\right)+k_{2}^{+}\left(y_{H_{2}}\left(\phi_{\max }-\phi\right)-\frac{1}{K_{2}} y_{H_{2} O} \phi\right)$

In equation (8) it is assumed that the maximal value of the fraction of the reduced centres is limited to $\phi_{\max }$. In the current study the maximal value $\phi_{\max }=0.9$ was used (Seidel et al. 2020). The equilibrium constants

$K_{1}=\frac{k_{1}^{+}}{k_{1}^{-}}=\left(\frac{-\Delta G_{1}}{R T}\right)$ 
$K_{2}=\frac{k_{2}^{+}}{k_{2}^{-}}=\left(\frac{-\Delta G_{2}}{R T}\right)$

were fitted separately to the steady state data (Seidel et al. 2018), whereas the dynamic rate constants $k_{1}{ }^{+}, k_{2}{ }^{+}$were fitted to dynamic data (Seidel et al. 2018).

Finally, also an ideal gas phase was assumed. Catalyst deactivation, and further side reactions were neglected. With all of these assumptions the following lumped reaction rate expression were obtained (Seidel et al. 2018, 2020):

- For the reaction of CO hydrogenation (Eq. (5))

$r_{1}=(1-\phi) k_{1}\left(p_{C O}{p_{H_{2}}}^{2}-\frac{1}{K_{P 1}} p_{C H_{3} O H}\right) \theta^{\odot} \theta^{\otimes^{4}}$

- For the reaction of $\mathrm{CO}_{2}$ hydrogenation (Eq. (6))

$r_{2}=\phi^{2} k_{2}\left(p_{\mathrm{CO}_{2}} p_{\mathrm{H}_{2}}{ }^{2}-\frac{1}{K_{\mathrm{P} 2}} \frac{p_{\mathrm{CH}_{3} \mathrm{OH}} p_{\mathrm{H}_{2} \mathrm{O}}}{p_{\mathrm{H}_{2}}}\right) \theta^{* 2} \theta^{\otimes}$

- For the reverse water-gas shift reaction (RWGS) (Eq. (7))

$r_{3}=\phi(1-\phi)^{-1} k_{3}\left(p_{C O_{2}}-\frac{1}{K_{P 3}} \frac{p_{C O} p_{H_{2} O}}{p_{H_{2}}}\right) \theta^{*} \theta^{\odot}$

The corresponding relative amounts of free active surface centres are given with the following expressions (Seidel et al., 2018):

$\begin{aligned} \theta^{\odot} & =\left(1+K_{\mathrm{CH}_{3} \mathrm{OH}}^{\odot} p_{\mathrm{CH}_{3} \mathrm{OH}}+K_{\mathrm{CO}_{2}}^{\odot} p_{\mathrm{CO}_{2}}+K_{\mathrm{CO}}^{\odot} p_{\mathrm{CO}}\right)^{-1} \\ \theta^{\otimes} & =\left(1+\sqrt{K_{\mathrm{H}_{2}} p_{\mathrm{H}_{2}}}\right)^{-1} \\ \theta^{*} & =\left(1+K_{\mathrm{CH}_{3} \mathrm{OH}}^{*} p_{\mathrm{CH}_{3} \mathrm{OH}}+K_{\mathrm{CO}_{2}}^{*} p_{\mathrm{CO}_{2}}+K_{\mathrm{H}_{2} \mathrm{O}} p_{\mathrm{H}_{2} \mathrm{O}}+\frac{K_{O} K_{\mathrm{H}_{2} \mathrm{O}}}{K_{\mathrm{H}_{2}}} \frac{p_{\mathrm{H}_{2} \mathrm{O}}}{p_{\mathrm{H}_{2}}}\right)^{-1}\end{aligned}$

The reaction rate constants $k_{j}$ were determined based on the modified Arrhenius equation:

$k_{j}=A_{k, j} \exp \left(-B_{j}\left(\frac{T_{r e f}}{T}-1\right)\right), j=1,2,3$

with the reference temperature $T_{r e f}=523.15 \mathrm{~K}$ (Seidel et al., 2018; Vollbrecht, 2007) and $j=1,2,3$ corresponding to $\mathrm{CO}$ hydrogenation, $\mathrm{CO}_{2}$ hydrogenation and reversed water-gas shift reaction, respectively.

The equilibrium constants of the chemical reactions defined by equations (5-7), as functions of temperature (Vollbrecht, 2007), are given in Appendix A.

The values of the kinetic parameters used in this paper are given in Table 1. These values are somewhat different than the ones reported in our previous publications (Seidel et al. 2018, 2020), 
as they have been refitted to the experimental data of Vollbrecht (2007), by using $\phi \leq 0.9$ in the constraint set of the nonlinear least squares problem. In Table 1, the specific amount of surface centres $q_{\text {sat }}$ is also given. 
Table 1. Parameters and constant used in kinetic model

\begin{tabular}{|c|c|c|}
\hline Parameter & Unit & Value \\
\hline$\phi_{\max }$ & - & 0.9 \\
\hline$A_{k, C O}$ & $\mathrm{~mol} / \mathrm{kg}_{\mathrm{cat} / \mathrm{s}} / \mathrm{bar}^{3}$ & 0.00673 \\
\hline$B_{C O}$ & - & 26.4549 \\
\hline$A_{k, \mathrm{CO}_{2}}$ & $\mathrm{~mol} / \mathrm{kg}_{\mathrm{cat} / \mathrm{s}} / \mathrm{bar}^{3}$ & 0.0430 \\
\hline $\mathrm{B}_{\mathrm{CO}_{2}}$ & - & 1.5308 \\
\hline$A_{k, R W G S}$ & $\mathrm{~mol} / \mathrm{kg}_{\mathrm{cat}} / \mathrm{s} / \mathrm{bar}$ & 0.0117 \\
\hline$B_{R W G S}$ & - & 15.6154 \\
\hline$\sqrt{K_{H 2}}$ & $\operatorname{bar}^{-1 / 2}$ & 1.1064 \\
\hline$K_{\mathrm{CH} 3 \mathrm{OH}}^{*}$ & bar $^{-1}$ & 0 \\
\hline$K_{\mathrm{H} 2 \mathrm{O}}$ & $\operatorname{bar}^{-1}$ & 0 \\
\hline$K_{O}$ & - & 0 \\
\hline$K_{C O}$ & bar $^{-1}$ & 0.1497 \\
\hline$K_{\mathrm{CH} 3 \mathrm{OH}}^{\odot}$ & bar $^{-1}$ & 0 \\
\hline$K_{\mathrm{CO} 2}^{*}$ & $\operatorname{bar}^{-1}$ & 0.0629 \\
\hline$K_{\mathrm{CO} 2}^{\odot}$ & $\operatorname{bar}^{-1}$ & 0 \\
\hline$\Delta G_{1}$ & $\mathrm{~kJ} / \mathrm{mol}$ & 0.336 \\
\hline$\Delta G_{2}$ & $\mathrm{~kJ} / \mathrm{mol}$ & 21.841 \\
\hline$k_{1}^{+}$ & $\mathrm{s}^{-1}$ & $79.17410^{-4}$ \\
\hline$k_{2}^{+}$ & $\mathrm{s}^{-1}$ & $1.8810^{-5}$ \\
\hline$q_{\text {sat }}$ & $\mathrm{mol} / \mathrm{kg}_{\text {cat }}$ & 0.98 \\
\hline
\end{tabular}




\section{Application of the NFR method to evaluate the potential of single input forced periodic operation of methanol synthesis reactor}

In this Chapter, the NFR method is applied for the analysis and evaluation of possible improvement of methanol production, for forced periodic operations with single input modulations. The analysis is performed for a laboratory-scale uniformly mixed reactor such as the Micro-Berty reactor, which was used for kinetic measurements (Vollbrecht, 2007) on which the kinetic model used in this study is based. Thus, the theoretical results present below will also serve as a basis for a planned later experimental validation using this same reactor type.

\subsection{Mathematical model}

The mathematical model of the catalytic reactor for methanol synthesis is based on the following assumptions (the assumptions listed here are consistent with the assumptions used for the kinetic model presented above):

- The reaction occurs in an isothermal and isobaric CSTR,

- The gas phase is ideal in the range of operation parameters,

- The adsorption equilibrium between the solid and the fluid phase exists,

- The adsorption processes follow the Langmuir-Hinshelwood mechanism with the maximal adsorption capacity $q_{\text {sat }}($ Table 1$)$,

- The catalyst deactivation can be neglected,

- The reaction mechanism is defined with equations (5-7) and all other reactions can be neglected.

The Micro-Berty reactor can be modelled as a continuous stirred tank reactor (CSTR). As stated above, the reactor system in which methanol synthesis occurs is established for the case when total pressure $\left(p_{t o t}\right)$ is constant

$p_{\text {tot }}=\sum_{i=1}^{6} p_{i}=$ const

Considering that during methanol synthesis the total number of moles is decreasing and that the total pressure is held constant, the volumetric outlet flow-rate is also changing.

The mathematical model of the analysed system can be described with the following equations:

- material balances for each component $i$

$V_{G} \frac{d p_{i}}{d t}+m_{c a t} q_{s a t} R T \sum_{l=1}^{6} \frac{\partial \theta_{i}}{\partial p_{l}} \frac{d p_{l}}{d t}=\dot{V}_{0} p_{i, 0}-\dot{V} p_{i}+m_{c a t} R T \sum_{j=1}^{3} v_{i j} r_{j}, \quad i=1, \ldots, 6$

- total material balance for the case when total pressure is held constant

$m_{\text {cat }} q_{s a t} R T \sum_{i=1}^{6} \sum_{l=1}^{6} \frac{\partial \theta_{i}}{\partial p_{l}} \frac{d p_{l}}{d t}=\dot{V}_{0} p_{t o t}-\dot{V} p_{t o t}+m_{c a t} R T \sum_{i=1}^{6} \sum_{j=1}^{3} v_{i j} r_{j}$ 
- the equation describing the catalyst dynamics

$\frac{d \phi}{d t}=k_{1}^{+}\left(\frac{p_{3}}{p_{\text {tot }}}\left(\phi_{\max }-\phi\right)-\frac{1}{K_{1}} \frac{p_{2}}{p_{\text {tot }}} \phi\right)+k_{2}^{+}\left(\frac{p_{4}}{p_{\text {tot }}}\left(\phi_{\max }-\phi\right)-\frac{1}{K_{2}} \frac{p_{5}}{p_{\text {tot }}} \phi\right)$

The outlet volumetric flow-rate $(\dot{V})$ is evaluated based on the total material balance (Eq. (20)) which can be reformulated as follows:

$\dot{V}=\dot{V}_{0}+m_{\text {cat }} \frac{R T}{p_{t o t}} \sum_{i=1}^{6} \sum_{j=1}^{3} v_{i j} r_{j}-m_{\text {cat }} q_{\text {sat }} \frac{R T}{p_{t o t}} \sum_{i=1}^{6} \sum_{l=1}^{6} \frac{\partial \theta_{i}}{\partial p_{l}} \frac{d p_{l}}{d t}$

In equations (18-20) $p_{i}$ represents the partial pressure of component $i$ ( $i=1$ for $\mathrm{CH}_{3} \mathrm{OH}, i=2$ for $\mathrm{CO}_{2}, i=3$ for $\mathrm{CO}, i=4$ for $\mathrm{H}_{2}, i=5$ for $\mathrm{H}_{2} \mathrm{O}$ and $i=6$ for $\mathrm{N}_{2}$ ).

The adsorption equilibrium is described with the competitive adsorption Langmuir isotherm. The elements of the Jacobian matrix, $\left(\frac{\partial \theta_{i}}{\partial p_{l}}\right)$ which are used in the mathematical model (Eqs. (19-20)), are given in Appendix B. In order to evaluate the total concentration of each component on the catalyst surface, it is necessary to determine the concentration of each component on each active surface centre of catalyst.

For analysis in the frequency domain, it is convenient to introduce dimensionless variables (defined in Tab. 2) and to use dimensionless mathematical model. The dimensionless input and output variables are defined as relative deviations from their steady-state values, as shown in Tab.2.

Table 2 The definitions of dimensionless variables

\begin{tabular}{|l||l||}
\hline Dimensionless variables & Definitions \\
\hline Partial pressure of component $i$ & $P_{i}=\frac{p_{i}-p_{i, s}}{p_{i, s}}, i=1, \ldots 6$ \\
\hline Partial pressure of component $i$ in the inlet stream & $P_{i, 0}=\frac{p_{i, 0}-p_{i 0, s}}{p_{i 0, s}}, i=1, \ldots 6$ \\
\hline Time & $\tau=\frac{t}{\tau_{0, s}}=\frac{t}{V_{G} / \dot{V}_{0, s}}$ \\
\hline Fraction of reduced centres on the catalyst surface & $\Phi=\frac{\phi-\phi_{s}}{\phi_{s}}$ \\
\hline Volumetric flow-rate of the inlet stream & $v_{0}=\frac{\dot{V}_{0}-\dot{V}_{0, s}}{\dot{V}_{0, s}}$ \\
\hline Volumetric flow-rate of the outlet stream & $\mathrm{v}=\frac{\dot{V}-\dot{V}_{s}}{\dot{V}_{s}}$ \\
\hline Frequency & $\omega=\omega_{d} \tau_{0, s}$ \\
\hline
\end{tabular}


The dimensionless frequency $(\omega)$ (Tab.2) is defined based on the steady-state residence time $\left(\tau_{0, s}\right)$ calculated using the steady-state inlet volumetric flow-rate $\left(\dot{V}_{0, s}\right)$ and volume of the reactor $\left(V_{G}\right)$, as follows:

$\tau_{0, s}=\frac{V_{G}}{\dot{V}_{0, S}}$

For applying the NFR analysis, all nonlinear terms in the mathematical model need to be given in the polynomial form or expanded in Taylor series around a previously established steady-state point (Petkovska and Seidel-Morgenstern, 2013; Nikolić, 2016; Petkovska et al., 2018). Therefore, the nonlinear terms (reaction rate expressions (Eqs. (11-13)) from the mathematical model (Eqs. (19-20)) are replaced by their Taylor series expansions, which are given in Appendix C.

After incorporating the dimensionless variables (Tab. 2) in the mathematical model equations (19-21) and expanding all nonlinear terms into Taylor series form, the following set of dimensionless model equations is obtained:

$$
\begin{aligned}
\frac{d P_{i}}{d \tau}+m_{c a t} q_{s a t} & \frac{R T}{V_{G}}\left[\sum_{l=1}^{6} \frac{p_{l, s}}{p_{i, s}} \frac{\partial \theta_{i}}{\partial p_{l}} \frac{d P_{l}}{d \tau}\right]+\frac{\dot{V}_{s}}{\dot{V}_{0, s}}\left(P_{i}+v+v P_{i}\right) \\
& -\frac{R T}{\dot{V}_{0, s} p_{i, s}} m_{c a t}\left(\sum_{l=1}^{6}\left(v_{i, 1} q_{l}+v_{i, 2} \vartheta_{l}+v_{i, 3} s_{l}\right) P_{l}+\left(v_{i, 1} q_{7}+v_{i, 2} \vartheta_{7}+v_{i, 3} s_{7}\right) \Phi\right) \\
& =\frac{p_{i 0, s}}{p_{i, s}}\left(P_{i, 0}+v_{0}+v_{0} P_{i, 0}\right) \\
& +\frac{R T}{\dot{V}_{0, s} p_{i, s}} m_{c a t}\left(\sum_{l=1}^{6} \sum_{k=l}^{6}\left(v_{i, 1} Q_{l k}+v_{i, 2} U_{l k}+v_{i, 3} S_{l k}\right) P_{l} P_{k}\right. \\
& \left.+\left(v_{i, 1} Q_{77}+v_{i, 2} U_{77}+v_{i, 3} S_{77}\right) \Phi^{2}+\Phi \sum_{l=1}^{6}\left(v_{i, 1} Q_{l 7}+v_{i, 2} U_{l 7}+v_{i, 3} S_{l 7}\right) P_{l}\right)+\cdots
\end{aligned}
$$

$i=1, \ldots, 6$ 


$$
\begin{aligned}
m_{\text {cat }} q_{s a t} \frac{\dot{V}_{0, s}}{V_{G}} \sum_{i=1}^{6} \sum_{l=1}^{6} p_{l, s} \frac{\partial \theta_{i}}{\partial p_{l}} \frac{d P_{l}}{d \tau}+\frac{\dot{V}_{s} p_{t o t}}{R T} v \\
\quad-m_{c a t} \sum_{i=1}^{6}\left(\sum_{l=1}^{6}\left(v_{i, 1} q_{l}+v_{i, 2} \vartheta_{l}+v_{i, 3} s_{l}\right) P_{l}+\left(v_{i, 1} q_{7}+v_{i, 2} \vartheta_{7}+v_{i, 3} s_{7}\right) \Phi\right) \\
=\frac{\dot{V}_{0, s} p_{t o t}}{R T} v_{o} \\
+m_{c a t} \sum_{i=1}^{6}\left(\sum_{l=1}^{6} \sum_{k=l}^{6}\left(v_{i, 1} Q_{l k}+v_{i, 2} U_{l k}+v_{i, 3} S_{l k}\right) P_{l} P_{k}\right. \\
\\
\left.+\left(v_{i, 1} Q_{77}+v_{i, 2} U_{77}+v_{i, 3} S_{77}\right) \Phi^{2}+\Phi \sum_{l=1}^{6}\left(v_{i, 1} Q_{l 7}+v_{i, 2} U_{l 7}+v_{i, 3} S_{l 7}\right) P_{l}\right)+\cdots
\end{aligned}
$$

$$
\begin{aligned}
\frac{d \Phi}{d \tau}+\left[E_{2}\right] P_{2}+ & {\left[-\frac{\left(\phi_{\max }-\phi_{s}\right)}{\phi_{s}} E_{1}\right] P_{3}+\left[-\frac{\left(\phi_{\max }-\phi_{s}\right)}{\phi_{s}} E_{3}\right] P_{4}+\left[E_{4}\right] P_{5} } \\
& +\left[E_{1}+E_{2}+E_{3}+E_{4}\right] \Phi=\left[-E_{2}\right] P_{3} \Phi+\left[-E_{1}\right] P_{2} \Phi+\left[-E_{3}\right] P_{4} \Phi+\left[-E_{4}\right] P_{5} \Phi
\end{aligned}
$$

The auxiliary coefficients $q, Q, \vartheta, U, s, S$ as well as the auxiliary parameters $E_{1}-E_{4}$ used in this dimensionless mathematical model (Eqs. (23-25) are given Appendices C and D.

\subsection{Inputs, outputs and frequency response functions (FRFs)}

The inputs which can be modulated for the analysed system are:

- partial pressure of $\mathrm{CO}_{2}$ in the feed stream,

- partial pressure of $\mathrm{CO}$ in the feed stream,

- partial pressure of $\mathrm{H}_{2}$ in the feed stream and

- total volumetric flow-rate of the feed stream.

The outputs of the analysed system are the following variables:

- the partial pressures of all components in the outlet stream,

- the fraction of reduced active surface centres of the catalyst in the reactor (which in fact represents the state of the catalyst in the reactor) and

- the volumetric flow-rate of the outlet stream.

The vectors of inputs $\mathbf{X}$ and outputs $\mathbf{Y}$ in the dimensionless form are defined, as follows: 


$$
\mathbf{X}=\left[\begin{array}{c}
P_{\mathrm{CO}_{2}, \mathrm{O}} \\
P_{\mathrm{CO}, 0} \\
P_{\mathrm{H}_{2}, 0} \\
v_{0}
\end{array}\right] \quad \mathbf{Y}=\left[\begin{array}{c}
P_{\mathrm{CH}_{3} \mathrm{OH}} \\
P_{\mathrm{CO}_{2}} \\
P_{\mathrm{CO}} \\
P_{\mathrm{H}_{2}} \\
P_{\mathrm{H}_{2} \mathrm{O}} \\
\Phi \\
v
\end{array}\right]
$$

The FRFs which correlate an output $y(y=1, \ldots, 7)$ with a modulated input $x(x=1, \ldots, 4)$ will be denoted as $G$-functions. For implementation of the NFR method for evaluating the potential forced periodic operations, it was necessary to derive:

- the first order frequency response functions marked as $G_{y, x}^{(1)}(\omega)$,

- the asymmetrical second order frequency response functions marked as $G_{y, x, x}^{(2)}(\omega,-\omega)$.

The $\boldsymbol{G}$-FRFs were derived by implementing a standard derivation procedure which was given in our previous publications (Petkovska and Seidel-Morgenstern, 2013; Nikolić, 2016; Petkovska et al., 2018).

\section{3. Derivation of the FRFs}

The periodic modulation of input $X_{x}$, defined as a dimensionless inlet partial pressure of $\mathrm{CO}_{2}$, $\mathrm{CO}$ or $\mathrm{H}_{2}$ (for $x=1,2$ or 3 ) or dimensionless flow-rate $(x=4)$, with a forcing frequency $\omega$ and forcing amplitude $A_{x}$, in the shape of a co-sinusoidal function of frequency, is defined as follows:

$$
X_{x}(\tau)=A_{x} \cos (\omega \tau)=\left(\frac{A_{x}}{2}\right) e^{j \omega \tau}+\left(\frac{A_{x}}{2}\right) e^{-j \omega \tau}
$$

In the cases when the partial pressure of one of the reactants is the modulated input, the partial pressure of the inert $\left(\mathrm{N}_{2}\right)$ is adjusted in order to assure isobaric conditions (constant total pressure) in the reactor.

For the general case, when input $X_{x}$ is periodically modulated, the output $Y_{y}$, based on the Volterra series (Volterra, 1959) can be written in the following way:

$Y_{y}=\left(\frac{A_{x}}{2}\right) e^{j \omega \tau} G_{y, x}^{(1)}(\omega)+\left(\frac{A_{x}}{2}\right) e^{-j \omega \tau} G_{y, x}^{(1)}(-\omega)+\cdots+2\left(\frac{A_{x}}{2}\right)^{2} e^{0} G_{y, x, x}^{(2)}(\omega,-\omega)+\cdots$

After substituting the definitions of the dimensionless input (Eq.(27)) and outputs (Eq.(28)) in the dimensionless mathematical model (Eq.(23-25)) and after collecting the terms with $A_{x} e^{j \omega}$, a set of linear algebraic equations, defining the first order $\boldsymbol{G}$-FRFs is obtained. This set of equations can be written in the matrix form given with Eq. (29): 


$$
\left[\begin{array}{ccc}
\alpha_{11} & \cdots & \alpha_{17} \\
\vdots & \ddots & \vdots \\
\alpha_{71} & \cdots & \alpha_{77}
\end{array}\right] \times\left[\begin{array}{ccc}
G_{1,1}^{(1)}(\omega) & \cdots & G_{1,4}^{(1)}(\omega) \\
\vdots & \ddots & \vdots \\
G_{7,1}^{(1)}(\omega) & \cdots & G_{7,4}^{(1)}(\omega)
\end{array}\right]=\left[\begin{array}{cccc}
0 & 0 & 0 & 0 \\
\frac{p_{C O_{2}, 0, s}}{p_{C O_{2}, s}} & 0 & 0 & \frac{p_{C O_{2}, 0, s}}{p_{C O_{2}, s}} \\
0 & \frac{p_{C O, 0, s}}{p_{C O, s}} & 0 & \frac{p_{C O, 0, s}}{p_{C O, s}} \\
0 & 0 & \frac{p_{H_{2}, 0, s}}{p_{H_{2}, s}} & \frac{p_{H_{2}, 0, s}}{p_{H_{2}, s}} \\
0 & 0 & 0 & 0 \\
0 & 0 & 0 & 0 \\
0 & 0 & 0 & \frac{\dot{V}_{0, s} p_{t o t}}{R T}
\end{array}\right]
$$

The solution of this matrix equation gives the matrix of all first order FRFs for all combinations of outputs and inputs:

$$
\left[\begin{array}{ccc}
G_{1,1}^{(1)}(\omega) & \cdots & G_{1,4}^{(1)}(\omega) \\
\vdots & \ddots & \vdots \\
G_{7,1}^{(1)}(\omega) & \cdots & G_{7,4}^{(1)}(\omega)
\end{array}\right]=\left[\begin{array}{ccc}
\alpha_{11} & \cdots & \alpha_{17} \\
\vdots & \ddots & \vdots \\
\alpha_{71} & \cdots & \alpha_{77}
\end{array}\right]^{-1} \times\left[\begin{array}{cccc}
0 & 0 & 0 & 0 \\
\frac{p_{C O_{2}, 0, s}}{p_{C O_{2}, s}} & 0 & 0 & \frac{p_{C O_{2}, 0, s}}{p_{C O_{2}, s}} \\
0 & \frac{p_{C O, 0, s}}{p_{C O, s}} & 0 & \frac{p_{C O, 0, s}}{p_{C O, s}} \\
0 & 0 & \frac{p_{H_{2}, 0, s}}{p_{H_{2}, s}} & \frac{p_{H_{2}, 0, s}}{p_{H_{2}, s}} \\
0 & 0 & 0 & 0 \\
0 & 0 & 0 & 0 \\
0 & 0 & 0 & \frac{\dot{V}_{0, s} p_{t o t}}{R T}
\end{array}\right]
$$

By collecting the non-periodic terms with $\left(\left(\frac{A_{x}}{2}\right)^{2} e^{0}\right)$, a set of linear algebraic equations defining the asymmetrical second order $\boldsymbol{G}$-FRFs is obtained, which are again written in the matrix form and given with Eq. (31):

$$
2 \times\left[\begin{array}{ccc}
\gamma_{11} & \cdots & \gamma_{17} \\
\vdots & \ddots & \vdots \\
\gamma_{71} & \cdots & \gamma_{77}
\end{array}\right] \times\left[\begin{array}{ccc}
G_{1,1,1}^{(2)}(\omega,-\omega) & \cdots & G_{1,4,4}^{(2)}(\omega,-\omega) \\
\vdots & \ddots & \vdots \\
G_{7,1,1}^{(2)}(\omega,-\omega) & \cdots & G_{7,4,4}^{(2)}(\omega,-\omega)
\end{array}\right]=\left[\begin{array}{ccc}
\Gamma_{11} & \cdots & \Gamma_{14} \\
\vdots & \ddots & \vdots \\
\Gamma_{71} & \cdots & \Gamma_{74}
\end{array}\right]
$$

The solution of this matrix equation results with a matrix of the ASO $G$-FRFs for all combinations of the inputs and outputs:

$$
\left[\begin{array}{ccc}
G_{1,1,1}^{(2)}(\omega,-\omega) & \cdots & G_{1,4,4}^{(2)}(\omega,-\omega) \\
\vdots & \ddots & \vdots \\
G_{7,1,1}^{(2)}(\omega,-\omega) & \cdots & G_{7,4,4}^{(2)}(\omega,-\omega)
\end{array}\right]=2 \times\left[\begin{array}{ccc}
\gamma_{11} & \cdots & \gamma_{17} \\
\vdots & \ddots & \vdots \\
\gamma_{71} & \cdots & \gamma_{77}
\end{array}\right]^{-1} \times\left[\begin{array}{ccc}
\Gamma_{11} & \cdots & \Gamma_{14} \\
\vdots & \ddots & \vdots \\
\Gamma_{71} & \cdots & \Gamma_{74}
\end{array}\right]
$$

The definitions of the coefficients $\alpha_{i j}$ used in equations (29) and (30) are given in Appendix $E$. The definitions of the coefficients $\gamma_{i j}$ used in equation (31) and (32) are given in Appendix $F$. 


\subsection{Identification and evaluation of regions of possible improvement}

The main goal of implementing forced periodic operations is to improve the reactor performance, e.g. through increase of methanol production, conversion or yield. All these performance criteria can be evaluated based on the time-average outlet molar flow-rate of methanol, which has been chosen as the main indicator of possible improvement that should be maximized.

The methanol molar flow-rate can be evaluated from the methanol partial pressure and volumetric flow-rate of the outlet stream:

$\dot{n}_{\mathrm{CH}_{3} \mathrm{OH}}=\frac{p_{\mathrm{CH}_{3} \mathrm{OH}} \dot{V}}{R T}$

It is convenient to use the dimensionless molar flow-rate of methanol, which is defined as a relative deviation from its steady-state value, in an analogous way as the dimensionless partial pressures (Table 2):

$\dot{N}_{\mathrm{CH} 3 \mathrm{OH}}=\frac{\dot{n}_{\mathrm{CH} 3 \mathrm{OH}}-\dot{n}_{\mathrm{CH} 3 \mathrm{OH}, \mathrm{S}}}{\dot{n}_{\mathrm{CH} 3 \mathrm{OH}, \mathrm{S}}}=\frac{p_{\mathrm{CH} 3 \mathrm{OH}} \dot{\mathrm{V}}-p_{\mathrm{CH} 3 \mathrm{OH}, \mathrm{S}} \dot{V}_{S}}{p_{\mathrm{CH} 3 \mathrm{OH}, \mathrm{S}} \dot{V}_{S}}=P_{\mathrm{CH} 3 \mathrm{OH}}+v+P_{\mathrm{CH} 3 \mathrm{OH}} v$

The non-periodic (DC) component of the outlet molar flow-rate of methanol, which is the measure of improvement of methanol production, can be evaluated in the following way:

$\dot{N}_{C H 3 O H, D C}=P_{C H 3 O H, D C}+v_{D C}+\left(P_{C H 3 O H} v\right)_{D C}$

The outlet molar flow-rate of methanol is an additional output which is of interest, which can be associated to additional sets of FRFs, which will be denoted as $H$-functions. If one of the inputs $X_{x}$ is modulated in a co-sinusoidal way, the DC component of outlet molar flow-rate of methanol can be approximately evaluated using the corresponding $\boldsymbol{H}$ ASO FRF:

$\dot{N}_{C H 3 O H, D C} \approx 2\left(\frac{A_{x}}{2}\right)^{2} H_{1, x, x}^{(2)}(\omega,-\omega)$

Based on equations (35 and 36) it is relatively easy to derive a relation between the $H$ ASO FRFs and the previously derived $\boldsymbol{G}$-FRFs, corresponding to the methanol partial pressure and the outlet flow-rate. The asymmetrical second order $H$-FRF is:

$H_{1, x, x}^{(2)}(\omega,-\omega)=G_{1, x, x}^{(2)}(\omega,-\omega)+G_{7, x, x}^{(2)}(\omega,-\omega)+\frac{1}{2}\left(G_{1, x}^{(1)}(\omega) G_{7, x}^{(1)}(-\omega)+G_{1, x}^{(1)}(-\omega) G_{7, x}^{(1)}(\omega)\right)$

$x=1,2,3$ or 4

Based on the NFR method, the mean (time-average) value of the outlet molar flow rate of methanol for co-sinusoidal modulation of input $X_{x}$, can be approximately calculated using the following expression:

$\left.\dot{(n}_{\mathrm{CH} 3 \mathrm{OH}}\right)_{\text {mean }} \approx \dot{n}_{\mathrm{CH} 3 \mathrm{OH}, \mathrm{S}}\left(1+2\left(\frac{A_{x}}{2}\right)^{2} H_{1, x, x}^{(2)}(\omega,-\omega)\right)$ 
where

$\dot{n}_{\mathrm{CH}_{3} \mathrm{OH}, \mathrm{S}}=\frac{p_{\mathrm{CH}_{3} \mathrm{OH}, \mathrm{S}} \dot{\mathrm{V}}_{S}}{R T}$

is the outlet molar flow-rate of methanol in steady state, while $\left(\dot{n}_{\mathrm{CH}_{3} \mathrm{OH}}\right)_{\text {mean }}$ is the time average value of the outlet molar flows-rate over an integer number of periods $P$ :

$\left(\dot{n}_{\mathrm{CH}_{3} \mathrm{OH}}\right)_{\text {mean }}=\frac{1}{P} \int_{k P}^{(k+1) P} \dot{n}_{\mathrm{CH}_{3} \mathrm{OH}}(t) d t=\frac{1}{P R T} \int_{k P}^{(k+1) P} p_{\mathrm{CH} 3 \mathrm{OH}}(t) \dot{V}(t) d t$

Based on the mean value of the methanol outlet molar flow rate, several performance indicators were defined. One of them is the normalized methanol production rate per unit mass of catalyst for the periodic operation (PO):

$\left(\dot{n}_{\mathrm{CH}}^{\text {norm } \mathrm{OH}}\right)_{P O}=\frac{\left(\dot{n}_{\mathrm{CH}_{3} \mathrm{OH}}\right)_{\text {mean }}}{m_{\text {cat }}}$

Other two performance indicators analysed are yield of methanol based of total carbon:

$\left(Y_{\mathrm{CH}_{3} \mathrm{OH}}^{\mathrm{tO} \mathrm{OH}}\right)_{\mathrm{PO}}=\frac{\left(\dot{n}_{\mathrm{CH} 3 \mathrm{OH}}\right)_{\text {mean }}}{\left(\dot{n}_{\mathrm{CO} 2}+\dot{n}_{\mathrm{CO}}\right)_{0, \text { mean }}}$

and yield of methanol based on hydrogen:

$\left(Y_{\mathrm{CH}_{3} \mathrm{OH}}^{\mathrm{H}_{2}}\right)_{P O}=2 \frac{\left(\dot{n}_{\mathrm{CH} 3 \mathrm{OH}}\right)_{\text {mean }}}{\left(\dot{n}_{\mathrm{H} 2,0}\right)_{\text {mean }}}$

It should be noticed that for single input modulations, the mean values of the molar flow-rates of the reactants in the feed stream are identical to their steady-state values. Using this fact and equation (38), the yields defined in equations (42) and (43) can be evaluated based on their steady-state values and function $H_{1, x, x}^{(2)}(\omega,-\omega)$ :

$\left(Y_{\mathrm{CH}_{3} O H}^{t o t C}\right)_{P O} \approx\left(Y_{\mathrm{CH}_{3} O H}^{t o t C}\right)_{S S}\left(1+2\left(\frac{A_{x}}{2}\right)^{2} H_{1, x, x}^{(2)}(\omega,-\omega)\right)$

and

$\left(Y_{\mathrm{CH}_{3} \mathrm{OH}}^{\mathrm{H}_{2}}\right)_{P O} \approx\left(Y_{\mathrm{CH}_{3} \mathrm{OH}}^{\mathrm{H}_{2}}\right)_{S S}\left(1+2\left(\frac{A_{x}}{2}\right)^{2} H_{1, x, x}^{(2)}(\omega,-\omega)\right)$

where

$\left(Y_{\mathrm{CH}_{3} \mathrm{OH}}^{\mathrm{tO} T \mathrm{H}}\right)_{S S}=\frac{\left(\dot{n}_{\mathrm{CH} 3 \mathrm{OH}}\right)_{s}}{\left(\dot{n}_{\mathrm{CO} 2}+\dot{n}_{\mathrm{CO}}\right)_{0, \mathrm{~S}}}$

and

$\left(Y_{\mathrm{CH}_{3} \mathrm{OH}}^{\mathrm{H}_{2}}\right)_{S S}=2 \frac{\left(\dot{n}_{\mathrm{CH} 3 \mathrm{OH}}\right)_{S}}{\dot{n}_{\mathrm{H} 2,0, \mathrm{~S}}}$ 
are the yields of methanol based on total carbon and based on hydrogen, respectively, corresponding to the chosen steady-state point.

Based on the sign of ASO $H$-FRF $H_{1, x, x}^{(2)}(\omega,-\omega)$, it is possible to predict whether the improvement owing to periodic modulation of the input $X_{x}$ is possible at all, or not (Petkovska and Seidel-Morgenstern, 2013; Nikolić, 2016; Petkovska et al., 2018). The improvement can be achieved only if $H_{1, x, x}^{(2)}(\omega,-\omega)$ is positive. 


\section{Simulation results and discussion}

In this Section, the simulation results based on the NFR analysis, for periodically operated isothermal, isobaric, lab-scale Micro-Berty reactor are given, for cases of single input modulations of the reactant partial pressures in the feed stream, or its volumetric flow-rate. The analysis was performed for a lab-scale reactor of the volume of the reaction mixture (i.e. gas phase) $V_{G}=10.3 \mathrm{ml}$ and with a mass of catalyst $m_{\text {cat }}=0.00395 \mathrm{~kg}$.

\subsection{Choosing the optimal steady-state for analysis}

The first step in the analysis of forced periodic operation is to determine the optimal steady state, around which the system inputs should be modulated.

The optimal steady-state was chosen based on multi-objective optimization with two objective functions: normalized outlet molar flow-rate of methanol $\left(\mathrm{mmol} /\left(\mathrm{min} \mathrm{kg}_{\mathrm{cat}}\right)\right)$ and yield of methanol based on total carbon, which both need to be maximized. The multi-objective optimization problem was solved using $\varepsilon$-Constraint method (Haimes et al., 1971). The variables optimized were the mole fractions of all reactants $\left(\mathrm{CO}_{2}, \mathrm{CO}\right.$ and $\left.\mathrm{H}_{2}\right)$ in feed stream and the reactor temperature. The values of reactor pressure, the flow-rate of the feed stream and the mole fraction of the inert $\left(\mathrm{N}_{2}\right)$ were fixed. The optimization was performed in the range of validity of the kinetic model (Vollbrecht, 2007, Seidel et al., 2018) (mole fractions of $\mathrm{CO}_{2}$ and $\mathrm{CO}$ between 0 and 1, mole fraction of $\mathrm{H}_{2}$ between 0.5 and 1 and temperature between 473 and $533 \mathrm{~K}$ ).

The resulting Pareto front with the marked selected optimal steady-state point is given in Appendix $G$ (Figure G.1). An overview of the optimization results for that selected steady-state point is given in Table 3 .

Table 3. Overview of the chosen optimal steady-state point for analysis.

\begin{tabular}{|c|c|c|c|c|c|c|}
\hline \multicolumn{7}{|c|}{ Fixed parameters } \\
\hline \multicolumn{2}{|c|}{$p_{t o t}(\mathrm{bar})$} & \multicolumn{3}{|c|}{$\dot{V}_{0, s}(\mathrm{ml} / \mathrm{min})$} & \multicolumn{2}{|c|}{$y_{N 2, s}$} \\
\hline \multicolumn{2}{|c|}{60} & \multicolumn{3}{|c|}{6.93} & \multicolumn{2}{|c|}{0.15} \\
\hline \multicolumn{7}{|c|}{ Optimization parameters } \\
\hline \multicolumn{2}{|c|}{$y_{C O 2, s}$} & \multicolumn{2}{|l|}{$y_{C O, s}$} & $y_{H 2, s}$ & \multicolumn{2}{|c|}{$T_{s}[\mathrm{~K}]$} \\
\hline \multicolumn{2}{|c|}{0.021} & 0.185 & & 0.644 & \multicolumn{2}{|c|}{473} \\
\hline \multicolumn{7}{|c|}{ Outputs } \\
\hline$y_{\mathrm{CH} 3 \mathrm{OH}, \mathrm{s}}$ & $y_{\mathrm{CO} 2, \mathrm{~s}}$ & $y_{\mathrm{CO}, \mathrm{s}}$ & $y_{\mathrm{H} 2, \mathrm{~s}}$ & $y_{\mathrm{H} 2 \mathrm{O}, \mathrm{s}}$ & $y_{\mathrm{N} 2, \mathrm{~s}}$ & $\begin{array}{c}\dot{V}_{\text {out }, s} \\
\mathrm{ml} / \mathrm{min}\end{array}$ \\
\hline 0.168 & 0.026 & 0.081 & 0.522 & 0.002 & 0.200 & 5.186 \\
\hline \multicolumn{7}{|c|}{ Performance indicators } \\
\hline
\end{tabular}




\begin{tabular}{|c|c|c|}
\hline$\left(\dot{n}_{\mathrm{CH} \mathrm{H}_{3} \mathrm{OH}}^{\text {norm }}\right)_{S S}\left[\mathrm{mmol} / \mathrm{min} / \mathrm{kg}_{\mathrm{cat}}\right]$ & $\left(\mathrm{Y}_{\mathrm{CH}_{3} \mathrm{OH}}^{\mathrm{totC}}\right)_{S S}(\%)$ & $\left(\mathrm{Y}_{\mathrm{CH}}^{\mathrm{H}_{2} \mathrm{OH}}\right)_{S S}(\%)$ \\
\hline 336.91 & 61.05 & 39.09 \\
\hline
\end{tabular}

\subsection{Results for single input modulations around their optimal steady-state values}

The simulation results of NFR analysis for single input modulations around optimal steady-state are presented here. The asymmetrical second order $\boldsymbol{H}$-FRFs which correlate the outlet molar flow-rate of methanol to the 4 inputs related to the feed reactor steam (partial pressures of $\mathrm{CO}_{2}$, $\mathrm{CO}, \mathrm{H}_{2}$ and the volumetric flow-rate), are given in Figure 1, as a function of dimensionless forcing frequency.

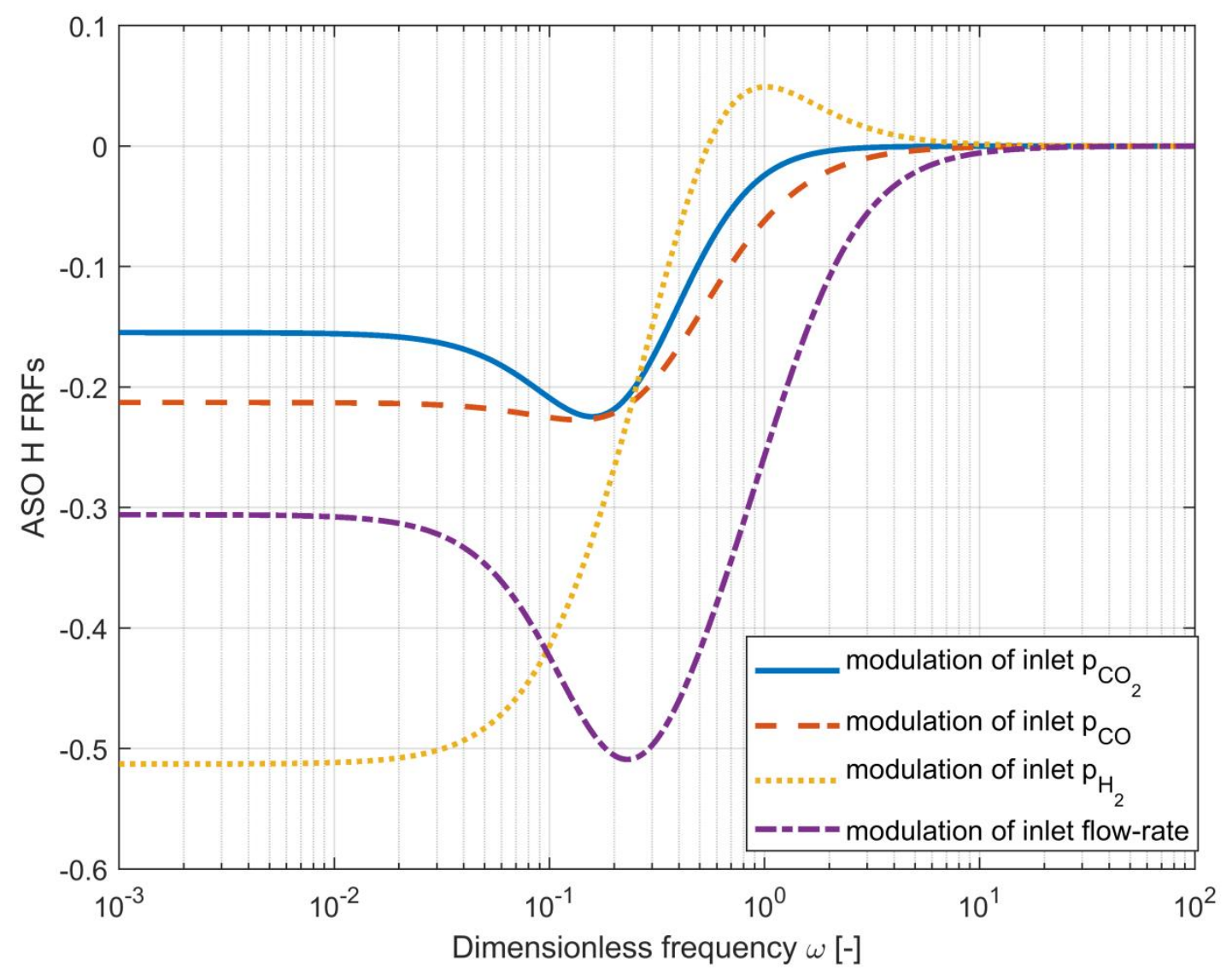

Figure 1. The asymmetrical second order $\boldsymbol{H}$ FRFs for single input modulations of partial pressures of $\mathrm{CO}_{2}, \mathrm{CO}$ and $\mathrm{H}_{2}$ or volumetric flow-rate around their optimal steady-state values, vs. dimensionless frequency.

As stated above, for the frequency range in which those $\boldsymbol{H}$-ASO FRFs $\left(H_{1, x, x}^{(2)}(\omega,-\omega), x=\right.$ $1, \ldots 4)$ are negative or equal to zero the improvement with single input modulations cannot be achieved, meaning that the steady-state operation is superior to periodic processes with any of the single input modulations. On the other hand, if $\boldsymbol{H}$-ASO FRFs are positive, the improvement could be obtained by periodic operations. 
Based on results presented in Fig.1, it can be concluded that:

- For single input modulations of $\mathrm{CO}_{2}, \mathrm{CO}$ and inlet volumetric flow-rate around the optimal stead-state, the $\boldsymbol{H}$-ASO FRFs which correlate the outlet molar flow-rate of methanol to modulated inputs $\left(H_{1,1,1}^{(2)}(\omega,-\omega), H_{1,2,2}^{(2)}(\omega,-\omega), H_{1,4,4}^{(2)}(\omega,-\omega)\right)$, are negative and tend to zero for high forcing frequencies. Consequently, periodic modulations of these inputs cannot improve the process of methanol synthesis.

- For single input modulation of $\mathrm{H}_{2}$ partial pressure around its optimal steady-state value, the corresponding $\boldsymbol{H}$-ASO FRF which correlates the outlet molar flow-rate of methanol to the modulated input $\left(H_{1,3,3}^{(2)}(\omega,-\omega)\right)$ is positive for forcing frequencies higher than 0.55 and also tends to zero for high forcing frequencies. The maximal value of this ASO FRF of 0.049 is obtained for dimensionless forcing frequency $\omega \approx 1$. The maximal possible increase of the normalized outlet molar flow rate of methanol corresponding to this is $0.13 \%$ (when the highest possible forcing amplitude is used), which is practically insignificant.

\subsection{Analysis of maximal possible improvement for single input modulations}

The results of the previous section show that, under the defined conditions, it is not possible to improve the reactor performance by periodic modulation of partial pressures of $\mathrm{CO}$ and $\mathrm{CO}_{2}$ or the volumetric flow-rate around the chosen optimal steady-state point, as corresponding ASO $\mathrm{H}$ FRFs are negative in the whole frequency range. Some insignificant improvement (maximal increase or the normalized outlet molar flow-rate of methanol is $0.13 \%$ ) is possible for periodic modulation of partial pressure of hydrogen, considering that the corresponding ASO $\mathrm{H}$-FRF is positive for some forcing frequencies (Figure 1).

Nevertheless, generally it would be possible that single input modulations around some other steady-state points would result with process improvement. In this section we explore these possibilities.

Considering the fact that, for periodic operations with single input modulations, the possible improvement is directly proportional to the corresponding ASO $\mathrm{H}$-FRF, four optimizations were performed, in which the conditions that maximize the ASO $\boldsymbol{H}$-FRFs for the four analysed inputs $\left(H_{1, x, x}^{(2)}(\omega,-\omega), x=1, \ldots 4\right)$ were determined. The optimization variables were the steady-state mole fractions of $\mathrm{CO}_{2}, \mathrm{CO}$ and $\mathrm{H}_{2}$ in the feed stream, the steady-state temperature and the forcing frequency.

The details about these steady-state points, for which maximal ASO $\boldsymbol{H}$-FRFs are obtained, can be found in the Supplementary material. 
The corresponding, maximized ASO $\boldsymbol{H}$-FRFs, for all four investigated inputs, are shown in Fig. 2 , as functions of dimensionless forcing frequency.

A short overview of these cases is given in Table 4. In this table, the maximal possible values of the normalized methanol flow-rate, yield of methanol based on total carbon and yield of methanol based on hydrogen, corresponding to the periodic operations defined in such a way that the ASO $H$-FRFs are maximized, are compared with their corresponding steady-state values. The performance criteria for the periodic operations were calculated for the frequencies corresponding to the maxima of the $H$-FRFs shown in Fig. 2, and for the maximal possible values of the amplitudes. The percentage of the maximal possible improvement (which is the same for all three performance indicators) is also given in the last column of Table 4.

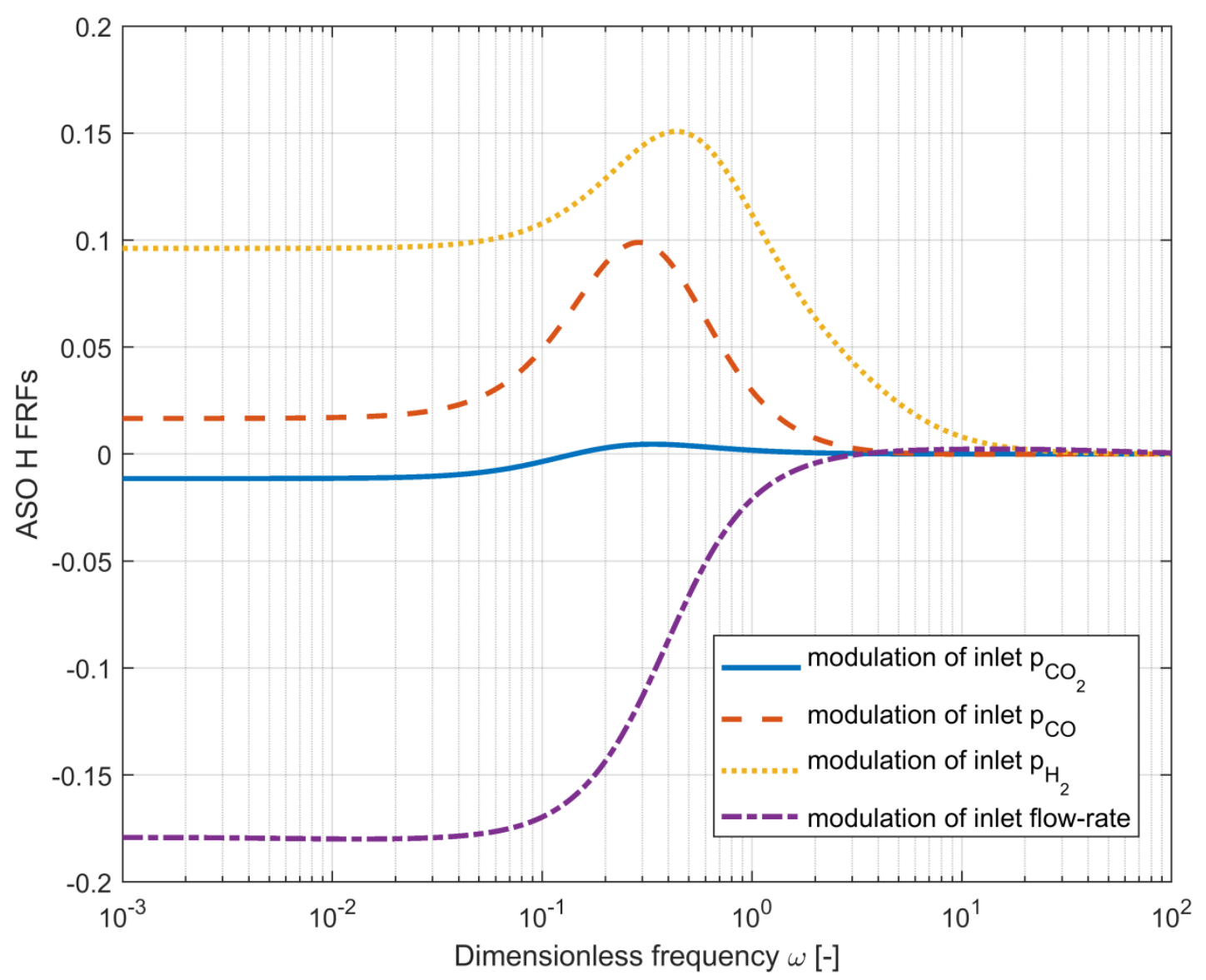

Figure 2. The maximal possible values of the asymmetrical second order $\boldsymbol{H}$-FRFs for single input modulations of the partial pressures of $\mathrm{CO}_{2}, \mathrm{CO}$ and $\mathrm{H}_{2}$ and volumetric flow-rate of the feed steam vs. dimensionless frequency.

Table 4. The normalized outlet molar flow-rate and yields of methanol based on total carbon and on hydrogen for the cases corresponding to the maximal ASO $H$-FRFs, for steady-state and periodic operations. 


\begin{tabular}{|c|c|c|c|c|c|c|c|}
\hline $\begin{array}{l}\text { Modulated } \\
\text { input }\end{array}$ & $\begin{array}{c}\left(\dot{n}_{\mathrm{CH}_{3} \mathrm{OH}}^{\text {orm }}\right)_{S S} \\
{\left[\begin{array}{c}\mathrm{mmol} / \mathrm{min} / \\
\left.\mathrm{kg}_{\mathrm{cat}}\right]\end{array}\right.}\end{array}$ & $\begin{array}{c}\left(Y_{\mathrm{CH}_{3} O H}^{t o t C}\right)_{S S} \\
\%\end{array}$ & $\begin{array}{c}\left(Y_{\mathrm{CH}_{3} \mathrm{OH}}^{\mathrm{H}_{2}}\right)_{S S} \\
\%\end{array}$ & $\begin{array}{c}\left(\dot{n}_{\mathrm{CH}_{3} \mathrm{OH}}^{\text {norm}}\right)_{P O} \\
{\left[\begin{array}{c}\mathrm{mmol}_{\mathrm{mmin}} / \\
\left.\mathrm{kg}_{\text {cat }}\right]\end{array}\right.}\end{array}$ & $\begin{array}{c}\left(Y_{\mathrm{CH}_{3} \mathrm{toH}}^{\mathrm{OtC}}\right)_{P O} \\
\%\end{array}$ & $\begin{array}{c}\left(Y_{\mathrm{CH}_{3} \mathrm{OH}}^{\mathrm{H}_{2}}\right)_{P O} \\
\%\end{array}$ & $\begin{array}{r}\text { Max } \\
\text { impr. } \\
{[\%]}\end{array}$ \\
\hline$P_{\mathrm{CO} 2}$ & 59.95 & 11.19 & 6.89 & 60.09 & 11.21 & 6.91 & 0.23 \\
\hline$P_{\mathrm{CO}}$ & 102.82 & 29.64 & 10.66 & 107.90 & 31.10 & 11.19 & 4.95 \\
\hline$P_{\mathrm{H} 2}$ & 261.72 & 27.93 & 39.11 & 263.50 & 28.12 & 39.37 & 0.68 \\
\hline$v_{0}$ & 7.69 & 28.89 & 0.68 & 7.70 & 28.92 & 0.69 & 0.12 \\
\hline
\end{tabular}

Based on the results presented in Fig. 2 it can be concluded that for single input modulations of inlet partial pressures of $\mathrm{CO}_{2}, \mathrm{CO}, \mathrm{H}_{2}$ or inlet volumetric flow-rate around the new steady-states determined in order to maximize the ASO $H$-FRFs improvement is possible for all cases, in certain ranges of forcing frequencies. On the other hand, the results presented in Table 4 show that the possible improvement is very small (the highest improvement is obtained for partial pressure of $\mathrm{CO}$ in the feed stream as the modulated input, and it is possible in the whole frequency range).

Nevertheless, despite the fact that some improvement is possible in comparison to the corresponding steady-states around which the four inputs should be modulated, all performance criteria corresponding to the periodic operations with modulation of the inlet partial pressures of $\mathrm{CO}_{2}, \mathrm{CO}, \mathrm{H}_{2}$ or the volumetric flow-rate of the feed stream, presented in Table 3, are by far worse than the performance criteria corresponding to the optimal steady-state defined in Section 5.1 (Table 3). So, the conclusion of this analysis is that none of these four periodic operations with single input modulations is acceptable.

\section{Conclusions}

The goal of this two-part manuscript is to present the results of a comprehensive study of the potential of using forced periodic operations in order to improve the performance of a chemical reactor for isothermal and isobaric methanol synthesis from syngas. Four potential forced periodic inputs are considered: partial pressures of all reactants $\left(\mathrm{CO}_{2}, \mathrm{CO}\right.$ and $\left.\mathrm{H}_{2}\right)$ in the feed stream and its total volumetric flow-rate. Because of the quantity of the obtained results, the manuscript needed to be split into two parts. 
In this first part of the manuscript, only the results for single input modulations are shown. Here are the most important results of this analysis:

- Periodic modulations of the partial pressures of $\mathrm{CO}_{2}, \mathrm{CO}$ and volumetric flow-rate of the feed stream, around the optimal steady state, always result with performance deterioration, instead of performance improvement, in the whole frequency range. Therefore, such periodic operations are unacceptable.

- Periodic modulation of the partial pressure of $\mathrm{H}_{2}$ around the optimal steady state could lead to improvement of the reactor performances for some forcing frequencies with the maximal possible improvement of $0.13 \%$ which is practically insignificant.

- It is possible to find some cases for which some limited improvement can be achieved with periodic modulations of the analysed inputs, if the inputs would be modulated around some other steady-state points. Nevertheless, all these cases correspond to reactor performances that are much worse than for the optimal steady-state process. Accordingly, these periodic operations are also unacceptable.

- Analysis of periodic operations with simultaneous modulation of two inputs is the next logical step, as it is a well-known fact that such operations have high potential for improvement (Petkovska and Seidel-Morgenstern, 2013; Felischak et al., 2021), owing to the cross-effect between the two modulated inputs, which can be easily adjusted by adjusting the phase difference between the two inputs. This analysis will be presented in the second part of our manuscript.

It is important to point out that frequency response functions for the four inputs, derived and presented here, are necessary for the analysis of the periodic operations with simultaneous modulation of two inputs, i.e. the analysis and results presented in Part II would not be possible without the results presented in Part I.

In both parts of our manuscript, the analysis was performed by using the nonlinear frequency response analysis. Even for a complex case, such as the reactor for methanol synthesis, with four potential modulated inputs and a large number of outputs, the NFR method was proven as a very useful and efficient tool for evaluating whether the reactor performance could be improved by using forced periodic operations, or not. 


\section{Nomenclature}

$A_{x}$

E

$G_{y, x}^{(n)}(\omega, \ldots, \omega)$

$\Delta G[\mathrm{~J} / \mathrm{mol}]$

$H_{i, x, x}^{(2)}(\omega, \ldots, \omega)$

J

$k_{j}$

$k_{1}^{+}, k_{2}^{+}\left[\mathrm{s}^{-1}\right]$

$K_{i}$

$K_{1}, K_{2}$

$K_{P i}\left[\mathrm{bar}^{-2}\right]$

$K_{P 3}[-]$

$m_{\text {cat }}[\mathrm{kg}]$

$\dot{n}[\mathrm{~mol} / \mathrm{s} ; \mathrm{mmol} / \mathrm{min}]$

$\dot{n}^{\text {norm }}\left[\mathrm{mmol} / \mathrm{min} / \mathrm{kg}_{\text {cat }}\right]$

$\dot{N}$

$p_{\text {tot }}[\mathrm{bar}]$

$p_{i}$ [bar]

$P_{i}[\mathrm{bar}]$

$q_{\text {sat }}[\mathrm{mol} / \mathrm{kg}]$

$q, Q, \vartheta, U, s, S$

$R[\mathrm{~J} / \mathrm{mol} / \mathrm{K}]$

$r_{j}\left[\mathrm{~mol} / \mathrm{kg}_{\mathrm{cat}} / \mathrm{s}\right]$ amplitude of input $x$ (partial pressure of $\mathrm{CO}_{2}, \mathrm{CO}$ or $\mathrm{H}_{2}$ or the volumetric flow rate)

auxiliary parameters for catalyst dynamic equation in dimensionless form

$n^{\text {th }}$ order FRF which correlate the output $y$ to modulated input $x$

Gibbs free energy

$\boldsymbol{H}$ ASO FRF which correlate the outlet molar flow-rate of component $i$ to modulated input $x$

Jacobian matrix

reaction rate constant $\left(j=1\right.$ for $\mathrm{CO}_{2}$ hydrogenation, $j=2$ for $\mathrm{CO}$ hydrogenation, $j=3$ for RWGS)

reaction rate constant for oxidation-reduction of catalyst

adsorption constant

equilibrium constants for oxidation-reduction of catalyst

reaction rate constant for $(i=1) \mathrm{CO}$ or $(i=2) \mathrm{CO}_{2}$ hydrogenation

reaction rate constant for RWGS

mass of catalyst

molar flow rate

normalized molar flow rate (per unit of mass of catalyst)

dimensionless molar flow rate

total pressure

partial pressure of component $i(i=1, \ldots, 6)$

dimensionless partial pressure of component $i(i=1, \ldots, 6)$

specific amount of surface centers

Taylor series coefficients for reaction rates

gas constant

rate of reaction $j\left(j=1\right.$ for $\mathrm{CO}$ hydrogenation, $j=2$ for $\mathrm{CO}_{2}$

hydrogenation, $j=3$ for RWGS)

$t[\mathrm{~s}] \quad$ time

$T[\mathrm{~K}] \quad$ temperature 


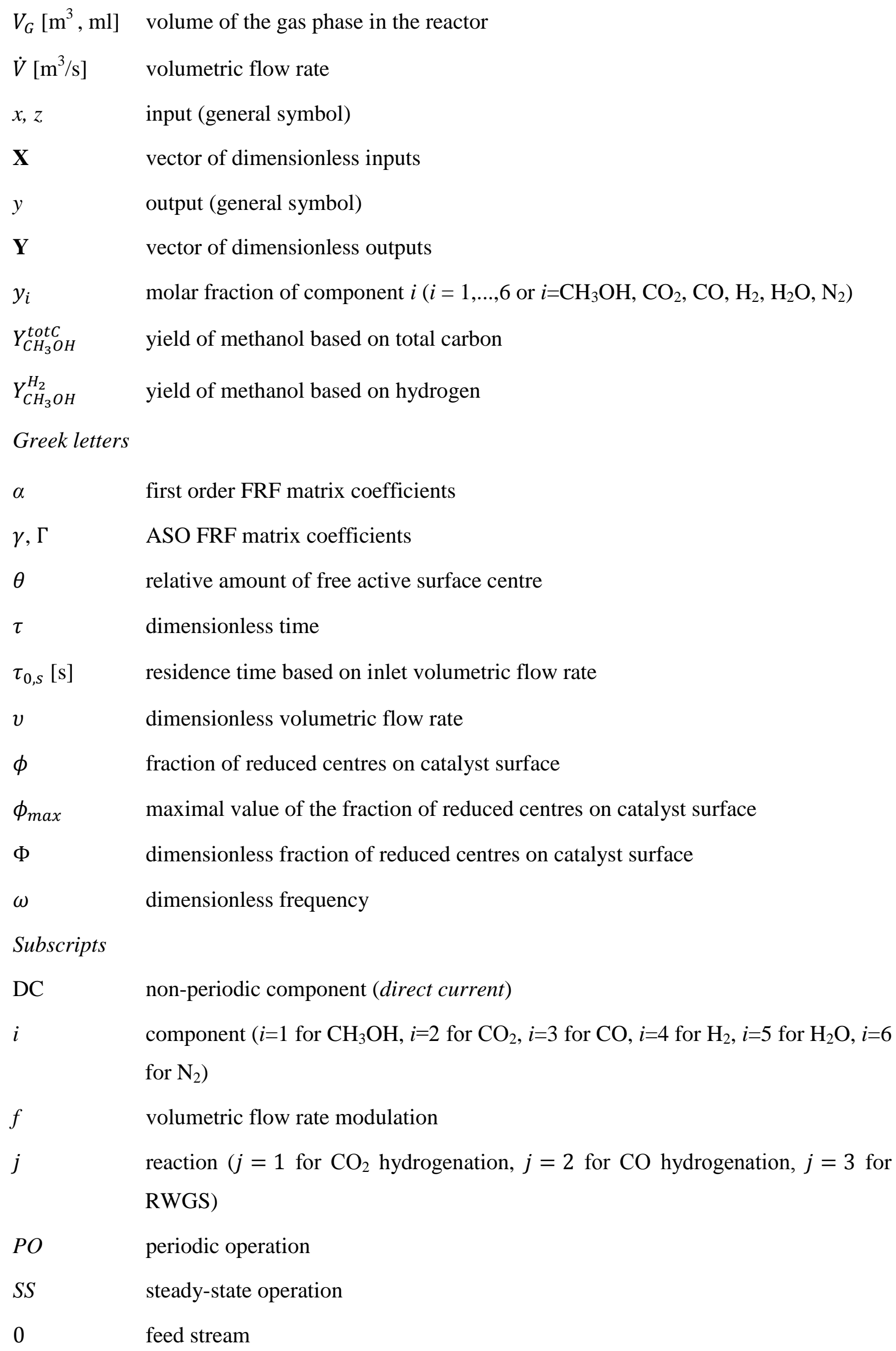




$\begin{array}{ll}\text { mean } & \text { mean value of periodic operation } \\ \text { ref } & \text { referent value } \\ s & \text { steady-state } \\ \text { tot } C & \text { total carbon }\end{array}$

Superscripts

$\begin{array}{ll}\mathrm{H}_{2} & \text { based on hydrogen } \\ \max & \text { maximal value } \\ \text { totC } & \text { based on total carbon } \\ * & \text { reduced surface centre } \\ \odot & \text { oxidized surface centre } \\ \otimes & \text { surface centre for hydrogen }\end{array}$

Abbreviations

AC Active centres on catalyst surface

ASO Asymmetrical Second Order

FRF Frequency Response Function

NFR Nonlinear Frequency Response

RWGS Reverse water-gas shift

\section{Acknowledgment}

This work is supported under the Priority Programme 2080 of the German Research Foundation DFG 'Catalysts and Reactors under Dynamic Operating Conditions for Energy Storage and Conversion' within the project 'Analysis of forced periodic operation of chemical reactors considering methanol synthesis as an example' under grants PE 2915/1-1, K1 417/6-1, SE 586/24-1.The engagement of Prof. Menka Petkovska was supported by the Ministry of Education, Science and Technological Development of the Republic of Serbia (Contract No.45103-9/2021-14/200135). 


\section{Appendix}

Appendix A - Temperature dependence of equilibrium constants of chemical reactions

[Vollbrecht, 2007]

$\log \left(K_{P 1}\right)=$

$13.814+\frac{3784.7}{T}-9.2833 \log (T)+3.147510^{-3} T-4.2613(10)^{-7} T^{2} \quad\left[\log \left(\mathrm{bar}^{-2}\right)\right]$

$\log \left(K_{P 2}\right)=$

$15.0921+\frac{1581.7}{T}-8.7639 \log (T)+2.110510^{-3} T-1.9303(10)^{-7} T^{2} \quad\left[\log \left(\mathrm{bar}^{-2}\right)\right]$

$\log \left(K_{P 3}\right)=1.2777-\frac{2167}{T}+0.5194 \log (T)-1.03710^{-3} T+2.33110^{-7} T^{2} \quad[-]$

\section{Appendix B Jacobian matrix}

In Appendix B, the Jacobian matrix is given, which elements $\left(\frac{\partial \theta_{l}}{\partial p_{i}}\right)$ are used in mathematical model (Eqs. 19-20). In order to evaluate the total concentration of each component on the catalyst surface, it is necessary to determine the concentration of each component on each active surface centre of catalyst.

The concentration of adsorbed component on catalyst surface $\left(\theta_{l}\right)$ based on Langmiur adsorption isotherm for competitive adsorption of multicomponent mixture is given with following expression:

$\theta_{l}=\frac{K_{l} p_{l}}{1+\sum_{i=1}^{6} K_{i} p_{i}}, \quad i, l=1, \ldots, 6$

The three active surface centres on catalyst are defined, and on each type of active centre the components which can be adsorbed are:

- on oxidized $\mathrm{AC}(\odot), \mathrm{CH}_{3} \mathrm{OH}, \mathrm{CO}_{2}$ and $\mathrm{CO}$ can be adsorbed,

- on reduced $\mathrm{AC}\left(^{*}\right), \mathrm{CH}_{3} \mathrm{OH}, \mathrm{CO}_{2}, \mathrm{H}_{2}$ and $\mathrm{H}_{2} \mathrm{O}$ can be adsorbed,

- on AC for RWGS reaction, $\mathrm{H}_{2}$ can be adsorbed. 


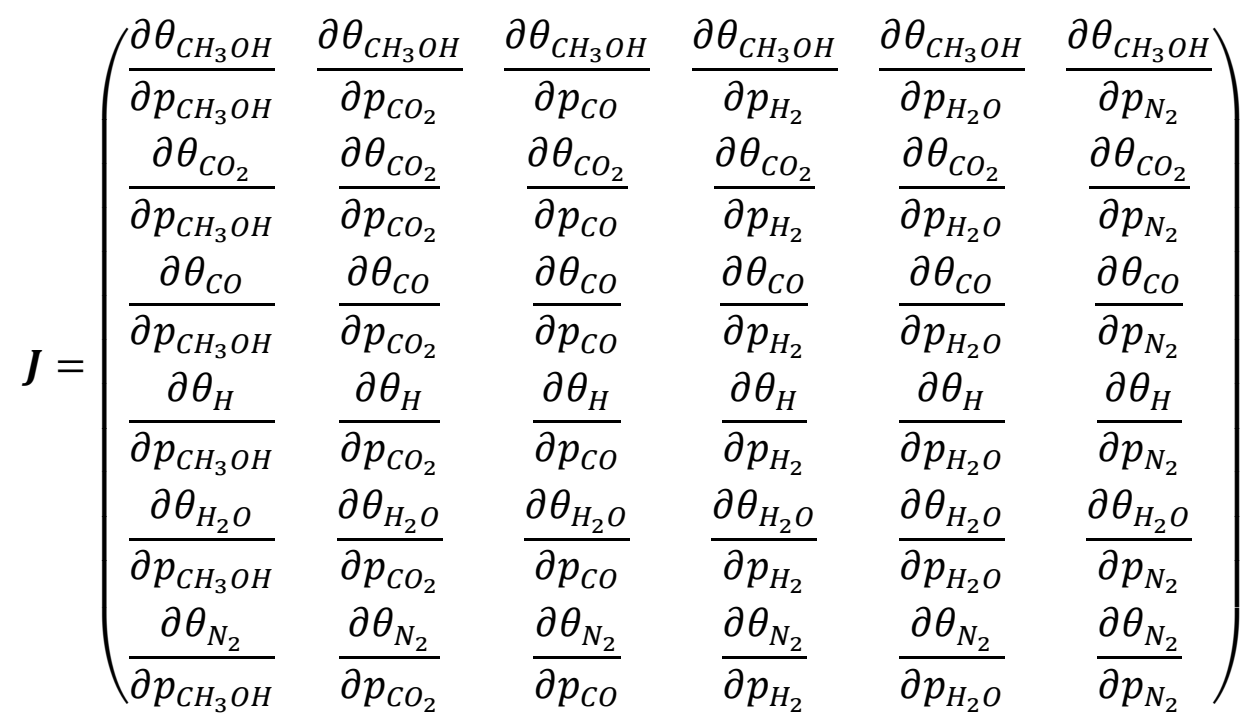

$$
\boldsymbol{J}=\boldsymbol{J}^{\odot}+\boldsymbol{J}^{\otimes}+\boldsymbol{J}^{*}
$$

$$
\boldsymbol{J}^{\odot}=\left(\begin{array}{cccccc}
\frac{\partial \theta_{\mathrm{CH}_{3} \mathrm{OH}}^{\odot}}{\partial p_{\mathrm{CH}_{3} \mathrm{OH}}} & \frac{\partial \theta_{\mathrm{CH}_{3} \mathrm{OH}}^{\odot}}{\partial p_{\mathrm{CO}_{2}}} & \frac{\partial \theta_{\mathrm{CH}_{3} \mathrm{OH}}^{\odot}}{\partial p_{\mathrm{CO}}} & 0 & 0 & 0 \\
\frac{\partial \theta_{\mathrm{CO}_{2}}^{\odot}}{\partial p_{\mathrm{CH}_{3} \mathrm{OH}}} & \frac{\partial \theta_{\mathrm{CO}_{2}}^{\odot}}{\partial p_{\mathrm{CO}_{2}}} & \frac{\partial \theta_{\mathrm{CO}_{2}}^{\odot}}{\partial p_{\mathrm{CO}}} & 0 & 0 & 0 \\
\frac{\partial \theta_{\mathrm{CO}}^{\odot}}{\partial p_{\mathrm{CH}_{3} \mathrm{OH}}} & \frac{\partial \theta_{\mathrm{CO}}^{\odot}}{\partial p_{\mathrm{CO}_{2}}} & \frac{\partial \theta_{\mathrm{CO}}^{\odot}}{\partial p_{\mathrm{CO}}} & 0 & 0 & 0 \\
0 & 0 & 0 & 0 & 0 & 0 \\
0 & 0 & 0 & 0 & 0 & 0 \\
0 & 0 & 0 & 0 & 0 & 0
\end{array}\right)
$$

$J(1,1)=\frac{\partial \theta_{\mathrm{CH}_{3} \mathrm{OH}}^{\odot}}{\partial p_{\mathrm{CH}_{3} \mathrm{OH}}}=K_{\mathrm{CH}_{3} \mathrm{OH}}^{\odot} \theta^{\odot}-K_{\mathrm{CH}_{3} \mathrm{OH}}^{\odot}{ }^{2} p_{\mathrm{CH}_{3} \mathrm{OH}} \theta^{\odot^{2}}$

$\boldsymbol{J}^{\odot}(1,2)=\frac{\partial \theta_{\mathrm{CH}_{3} \mathrm{OH}}^{\odot}}{\partial p_{\mathrm{CO}_{2}}}=-K_{\mathrm{CH}_{3} \mathrm{OH}}^{\odot} K_{\mathrm{CO}_{2}}^{\odot} p_{\mathrm{CH}_{3} \mathrm{OH}} \theta^{\odot}$

$J^{\odot}(1,3)=\frac{\partial \theta_{\mathrm{CH}_{3} \mathrm{OH}}^{\odot}}{\partial p_{\mathrm{CO}}}=-K_{\mathrm{CH}_{3} \mathrm{OH}}^{\odot} K_{\mathrm{CO}}^{\odot} p_{\mathrm{CH}_{3} \mathrm{OH}} \theta^{\odot^{2}}$

$J^{\odot}(2,1)=\frac{\partial \theta_{\mathrm{CO}_{2}}^{\odot}}{\partial p_{\mathrm{CH}_{3} \mathrm{OH}}}=-K_{\mathrm{CO}_{2}}^{\odot} K_{\mathrm{CH}_{3} \mathrm{OH}}^{\odot} p_{\mathrm{CO}_{2}} \theta^{\odot^{2}}$

$J^{\odot}(2,2)=\frac{\partial \theta_{\mathrm{CO}_{2}}^{\odot}}{\partial p_{\mathrm{CO}_{2}}}=K_{\mathrm{CO}_{2}}^{\odot} \theta^{\odot}-K_{\mathrm{CO}_{2}}^{\odot} p_{\mathrm{CO}_{2}} \theta^{\odot^{2}}$

$J^{\odot}(2,3)=\frac{\partial \theta_{\mathrm{CO}_{2}}^{\odot}}{\partial p_{\mathrm{CO}}}=-K_{\mathrm{CO}_{2}}^{\odot} K_{\mathrm{CO}}^{\odot} p_{\mathrm{CO}_{2}} \theta^{\odot^{2}}$ 


$$
\begin{aligned}
& \boldsymbol{J}^{\odot}(3,1)=\frac{\partial \theta_{\mathrm{CO}}^{\odot}}{\partial p_{\mathrm{CH}_{3} \mathrm{OH}}}=-K_{\mathrm{CO}}^{\odot} K_{\mathrm{CH}_{3} \mathrm{OH}}^{\odot} p_{\mathrm{CO}} \theta^{\odot} \\
& J^{\odot}(3,2)=\frac{\partial \theta_{C O}^{\odot}}{\partial p_{C O_{2}}}=-K_{C O}^{\odot} K_{C O_{2}}^{\odot} p_{C O} \theta^{\odot} \\
& \boldsymbol{J}^{\odot}(3,3)=\frac{\partial \theta_{C O}^{\odot}}{\partial p_{C O}}=K_{C O}^{\odot} \theta^{\odot}-K_{C O}^{\odot}{ }^{2} p_{C O} \theta^{\odot} \\
& \boldsymbol{J}^{\otimes}=\left(\begin{array}{cccccc}
0 & 0 & 0 & 0 & 0 & 0 \\
0 & 0 & 0 & 0 & 0 & 0 \\
0 & 0 & 0 & 0 & 0 & 0 \\
0 & 0 & 0 & \frac{\partial \theta_{H}}{\partial p_{H_{2}}} & 0 & 0 \\
0 & 0 & 0 & 0 & 0 & 0 \\
0 & 0 & 0 & 0 & 0 & 0
\end{array}\right) \\
& J^{\otimes}(4,4)=\frac{\partial \theta_{H}^{\otimes}}{\partial p_{H_{2}}}=\frac{1}{2} \sqrt{K_{H_{2}}} p_{H_{2}}{ }^{-1 / 2} \theta^{\otimes}-\frac{1}{2} K_{H_{2}} \theta^{\otimes^{2}} \\
& \boldsymbol{J}^{*}=\left(\begin{array}{cccccc}
\frac{\partial \theta_{\mathrm{CH}}^{*} \mathrm{OH}}{\partial p_{\mathrm{CH}} \mathrm{OH}} & \frac{\partial \theta_{\mathrm{CH}_{3} \mathrm{OH}}^{*}}{\partial p_{\mathrm{CO}_{2}}} & 0 & \frac{\partial \theta_{\mathrm{CH}_{3} \mathrm{OH}}^{*}}{\partial p_{\mathrm{H}_{2}}} & \frac{\partial \theta_{\mathrm{CH}_{3} \mathrm{OH}}^{*}}{\partial p_{\mathrm{H}_{2} \mathrm{O}}} & 0 \\
\frac{\partial \theta_{\mathrm{CO}}}{\partial p_{\mathrm{CH}_{3} \mathrm{OH}}} & \frac{\partial \theta_{\mathrm{CO}_{2}}^{*}}{\partial p_{\mathrm{CO}_{2}}} & 0 & \frac{\partial \theta_{\mathrm{CO}_{2}}}{\partial p_{\mathrm{H}_{2}}} & \frac{\partial \theta_{\mathrm{CO}}}{\partial p_{\mathrm{H}_{2} \mathrm{O}}} & 0 \\
0 & 0 & 0 & 0 & 0 & 0 \\
\frac{\partial \theta_{\mathrm{H}}^{*}}{\partial p_{\mathrm{CH}} \mathrm{OH}} & \frac{\partial \theta_{\mathrm{H}}^{*}}{\partial p_{\mathrm{CO}_{2}}} & 0 & \frac{\partial \theta_{\mathrm{H}}^{*}}{\partial p_{\mathrm{H}_{2}}} & \frac{\partial \theta_{\mathrm{H}}^{*}}{\partial p_{\mathrm{H}_{2} \mathrm{O}}} & 0 \\
\frac{\partial \theta_{\mathrm{H}_{2} \mathrm{O}}^{*}}{\partial p_{\mathrm{CH}_{3} \mathrm{OH}}} & \frac{\partial \theta_{\mathrm{H}_{2} \mathrm{O}}^{*}}{\partial p_{\mathrm{CO}_{2}}} & 0 & \frac{\partial \theta_{\mathrm{H}_{2} \mathrm{O}}}{\partial p_{\mathrm{H}_{2}}} & \frac{\partial \theta_{\mathrm{H}_{2} \mathrm{O}}}{\partial p_{\mathrm{H}_{2} \mathrm{O}}} & 0 \\
0 & 0 & 0 & 0 & 0 & 0
\end{array}\right) \\
& \boldsymbol{J}^{*}(1,1)=\frac{\partial \theta_{\mathrm{CH}_{3} \mathrm{OH}}^{*}}{\partial p_{\mathrm{CH}_{3} \mathrm{OH}}}=K_{\mathrm{CH}_{3} \mathrm{OH}}^{*} \theta^{*}-K_{\mathrm{CH}_{3} \mathrm{OH}}^{*} p_{\mathrm{CH}_{3} \mathrm{OH}} \theta^{* 2} \\
& \boldsymbol{J}^{*}(1,2)=\frac{\partial \theta_{\mathrm{CH}_{3} \mathrm{OH}}^{*}}{\partial p_{\mathrm{CO}_{2}}}=-K_{\mathrm{CH}_{3} \mathrm{OH}}^{*} K_{\mathrm{CO}_{2}}^{*} p_{\mathrm{CH}_{3} \mathrm{OH}} \theta^{* 2} \\
& \boldsymbol{J}^{*}(1,4)=\frac{\partial \theta_{\mathrm{CH}_{3} \mathrm{OH}}^{*}}{\partial p_{\mathrm{H}_{2}}}=K_{\mathrm{CH}_{3} \mathrm{OH}}^{*} p_{\mathrm{CH}_{3} \mathrm{OH}} \frac{K_{\mathrm{H}_{2} \mathrm{O} K_{\mathrm{O}}}}{K_{\mathrm{H}_{2}}} \frac{p_{\mathrm{H}_{2} \mathrm{O}}}{p_{\mathrm{H}_{2}}{ }^{2}} \theta^{* 2}
\end{aligned}
$$

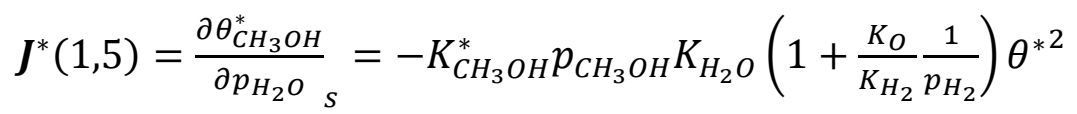

$$
\begin{aligned}
& J^{*}(2,1)=\frac{\partial \theta_{\mathrm{CO}_{2}}^{*}}{\partial p_{\mathrm{CH}_{3} \mathrm{OH}}}=-K_{\mathrm{CO}_{2}}^{*} K_{\mathrm{CH}_{3} \mathrm{OH}}^{*} p_{\mathrm{CO}_{2}} \theta^{* 2} \\
& \boldsymbol{J}^{*}(2,2)=\frac{\partial \theta_{\mathrm{CO}_{2}}^{*}}{\partial p_{\mathrm{CO}_{2}}}=K_{\mathrm{CO}_{2}}^{*} \theta^{*}-K_{\mathrm{CO}_{2}}^{*}{ }^{2} p_{\mathrm{CO}_{2}} \theta^{* 2} \\
& \boldsymbol{J}^{*}(2,4)=\frac{\partial \theta_{\mathrm{CO}_{2}}^{*}}{\partial p_{\mathrm{H}_{2}}}=K_{\mathrm{CO}_{2}}^{*} p_{\mathrm{CO}_{2}} \frac{K_{\mathrm{H}_{2} \mathrm{O} K_{\mathrm{O}}}}{K_{\mathrm{H}_{2}}} \frac{p_{\mathrm{H}_{2} \mathrm{O}}}{{p_{\mathrm{H}_{2}}}^{2}} \theta^{* 2} \\
& \boldsymbol{J}^{*}(2,5)=\frac{\partial \theta_{\mathrm{CO}_{2}}^{*}}{\partial p_{\mathrm{H}_{2} \mathrm{O}}}=-K_{\mathrm{CO}_{2}}^{*} p_{\mathrm{CO}_{2}} K_{\mathrm{H}_{2} \mathrm{O}}\left(1+\frac{K_{\mathrm{O}}}{K_{\mathrm{H}_{2}}} \frac{1}{p_{\mathrm{H}_{2}}}\right) \theta^{* 2}
\end{aligned}
$$




$$
\begin{aligned}
& \boldsymbol{J}^{*}(4,1)=\frac{\partial \theta_{\mathrm{H}}^{*}}{\partial p_{\mathrm{CH}_{3} \mathrm{OH}}}=-\sqrt{K_{\mathrm{H}_{2}}} K_{\mathrm{CH}_{3} \mathrm{OH}}^{*} \sqrt{p_{\mathrm{H}_{2}}} \theta^{* 2} \\
& \boldsymbol{J}^{*}(4,2)=\frac{\partial \theta_{\mathrm{H}}^{*}}{\partial p_{\mathrm{CO}_{2}}}=-\sqrt{K_{\mathrm{H}_{2}}} K_{\mathrm{CO}_{2}}^{*} \sqrt{p_{\mathrm{H}_{2}}} \theta^{*^{2}} \\
& \boldsymbol{J}^{*}(4,4)=\frac{\partial \theta_{\mathrm{H}}^{*}}{\partial p_{\mathrm{H}_{2}}}=\frac{1}{2} \sqrt{K_{\mathrm{H}_{2}}} p_{\mathrm{H}_{2}}^{-1 / 2} \theta^{*}+\sqrt{K_{\mathrm{H}_{2}} p_{\mathrm{H}_{2}}} \frac{K_{\mathrm{H}_{2} \mathrm{O}} K_{\mathrm{O}}}{K_{\mathrm{H}_{2}}} \frac{p_{\mathrm{H}_{2} \mathrm{O}}}{p_{\mathrm{H}_{2}}{ }^{2}} \theta^{* 2} \\
& \boldsymbol{J}^{*}(4,5)=\frac{\partial \theta_{H}^{*}}{\partial p_{\mathrm{H}_{2} \mathrm{O}}}=-\sqrt{K_{\mathrm{H}_{2}}} K_{\mathrm{H}_{2} \mathrm{O}}\left(1+\frac{K_{O}}{K_{\mathrm{H}_{2}}} \frac{1}{p_{H_{2}}}\right) p_{H 2}^{1 / 2} \theta^{*^{2}} \\
& \boldsymbol{J}^{*}(5,1)=\frac{\partial \theta_{\mathrm{H}_{2} \mathrm{O}}^{*}}{\partial p_{\mathrm{CH}_{3} \mathrm{OH}}}=-K_{\mathrm{H}_{2} \mathrm{O}} K_{\mathrm{CH}_{3} \mathrm{OH}}^{*} p_{\mathrm{H}_{2} \mathrm{O}} \theta^{* 2} \\
& \boldsymbol{J}^{*}(5,2)=\frac{\partial \theta_{\mathrm{H}_{2} \mathrm{O}}^{*}}{\partial p_{\mathrm{CO}_{2}}}=-K_{\mathrm{H}_{2} \mathrm{O}} K_{\mathrm{CO}_{2}}^{*} p_{\mathrm{H}_{2} \mathrm{O}} \theta^{* 2} \\
& \boldsymbol{J}^{*}(5,4)=\frac{\partial \theta_{\mathrm{H}_{2} \mathrm{O}}^{*}}{\partial p_{\mathrm{H}_{2}}}=K_{\mathrm{H}_{2} \mathrm{O}} p_{\mathrm{H}_{2} \mathrm{O}} \frac{K_{\mathrm{H}_{2} \mathrm{O}} K_{\mathrm{O}}}{K_{\mathrm{H}_{2}}} \frac{p_{\mathrm{H}_{2} \mathrm{O}}}{{p_{\mathrm{H}_{2}}{ }^{2}}^{2}} \theta^{* 2} \\
& \boldsymbol{J}^{*}(5,5)=\frac{\partial \theta_{\mathrm{H}_{2} \mathrm{O}}^{*}}{\partial p_{\mathrm{H}_{2} \mathrm{O}}}=K_{\mathrm{H}_{2} \mathrm{O}} \theta^{*}-K_{\mathrm{H}_{2} \mathrm{O}}{ }^{2} p_{\mathrm{H}_{2} \mathrm{O}}\left(1+\frac{K_{O}}{K_{\mathrm{H}_{2}}} \frac{1}{p_{\mathrm{H}_{2}}}\right) \theta^{* 2}
\end{aligned}
$$

Appendix C Taylor series expansion of nonlinear terms (reaction rates expressions)

For the multi-variables function $f(x, y, \ldots z)$, the Taylor expansion is defined as:

$$
\begin{aligned}
f(x, y, \ldots z),= & f\left(x_{s}, y_{s}, \ldots z_{s}\right),+\left(\frac{\partial f}{\partial x}\right)_{x_{s}, y_{s}, \ldots z_{s}}\left(x-x_{s}\right)+\left(\frac{\partial f}{\partial y}\right)_{x_{s}, y_{s}, \ldots z_{s}}\left(y-y_{s}\right)+\cdots \\
& +\left(\frac{\partial f}{\partial z}\right)_{x_{s}, y_{s}, . . z_{s}}\left(z-z_{s}\right)+\left(\frac{\partial^{2} f}{\partial x^{2}}\right)_{x_{s}, y_{s}, \ldots z_{s}} \frac{\left(x-x_{s}\right)^{2}}{2 !}+\left(\frac{\partial^{2} f}{\partial y^{2}}\right)_{x_{s}, y_{s}, \ldots z_{s}} \frac{\left(y-y_{s}\right)^{2}}{2 !} \\
& +\cdots+\left(\frac{\partial^{2} f}{\partial z^{2}}\right)_{x_{s}, y_{s}, . . z_{s}} \frac{\left(z-z_{s}\right)^{2}}{2 !}+\left(\frac{\partial^{2} f}{\partial x \partial y}\right)_{x_{s}, y_{s}, \ldots z_{s}}\left(x-x_{s}\right)\left(y-y_{s}\right)+\cdots \\
& +\left(\frac{\partial^{2} f}{\partial x \partial z}\right)_{x_{s}, y_{s}, \ldots z_{s}}\left(x-x_{s}\right)\left(z-z_{s}\right)+\cdots+\left(\frac{\partial^{2} f}{\partial y \partial z}\right)_{x_{s}, y_{s}, \ldots z_{s}}\left(y-y_{s}\right)\left(z-z_{s}\right)+\cdots
\end{aligned}
$$

The nonlinear terms (reaction rate expressions) are expanded in Taylor series up to second order (which are necessary for derivation of second order FRFs) around the steady state values and given in Appendix C.1-C.3.

\section{Appendix C.1.Taylor series expansion of the expression for the reaction rate of $\mathrm{CO}$}

\section{hydrogenation (Eq.11)}

Taylor series expansion of the expression for the reaction rate of CO hydrogenation is given here. 


$$
\begin{aligned}
& r_{1}=(1-\phi) k_{1}\left(p_{3} p_{4}^{2}-\frac{1}{K_{P 1}} p_{1}\right) \theta^{\odot} \theta^{\otimes} \\
& f_{1, s}=\left(1-\phi_{s}\right) k_{1}\left(p_{3, s} p_{4, s}^{2}-\frac{1}{K_{P 1}} p_{1, s}\right) \\
& r_{1} \approx r_{1, S}+q_{1} P_{C_{3} \mathrm{OH}}+q_{2} P_{\mathrm{CO}_{2}}+q_{3} P_{\mathrm{CO}}+q_{4} P_{\mathrm{H}_{2}}+q_{5} P_{\mathrm{H}_{2} \mathrm{O}}+q_{6} P_{\mathrm{N}_{2}}+q_{7} \Phi+Q_{11} P_{\mathrm{CH}_{3} \mathrm{OH}}{ }^{2} \\
& +Q_{22} P_{\mathrm{CO}_{2}}{ }^{2}+Q_{33} P_{\mathrm{CO}}{ }^{2}+Q_{44}{P_{\mathrm{H}_{2}}}^{2}+Q_{55} P_{\mathrm{H}_{2} \mathrm{O}}{ }^{2}+Q_{66}{P_{N_{2}}}^{2}+Q_{77} \Phi^{2} \\
& +Q_{12} P_{\mathrm{CH}_{3} \mathrm{OH}} P_{\mathrm{CO}_{2}}+Q_{13} P_{\mathrm{CH}_{3} \mathrm{OH}} P_{\mathrm{CO}}+Q_{14} P_{\mathrm{CH}_{3} \mathrm{OH}} P_{\mathrm{H}_{2}}+Q_{15} P_{\mathrm{CH}_{3} \mathrm{OH}} P_{\mathrm{H}_{2} \mathrm{O}} \\
& +Q_{16} P_{C_{3} \mathrm{OH}} P_{\mathrm{N}_{2}}+Q_{23} P_{\mathrm{CO}_{2}} P_{\mathrm{CO}}+Q_{24} P_{\mathrm{CO}_{2}} P_{\mathrm{H}_{2}}+Q_{25} P_{\mathrm{CO}_{2}} P_{\mathrm{H}_{2} \mathrm{O}}+Q_{26} P_{\mathrm{CO}_{2}} P_{N_{2}} \\
& +Q_{34} P_{C O} P_{H_{2}}+Q_{35} P_{C O} P_{H_{2} O}+Q_{36} P_{C O} P_{N_{2}}+Q_{45} P_{H_{2}} P_{H_{2} O}+Q_{46} P_{H_{2}} P_{N_{2}} \\
& +Q_{56} P_{\mathrm{H}_{2} \mathrm{O}} P_{\mathrm{N}_{2}}+Q_{17} P_{\mathrm{CH}_{3} \mathrm{OH}} \Phi+Q_{27} P_{\mathrm{CO}_{2}} \Phi+Q_{37} P_{\mathrm{CO}} \Phi+Q_{47} P_{\mathrm{H}_{2}} \Phi+Q_{57} P_{\mathrm{H}_{2} \mathrm{O}} \Phi \\
& +Q_{67} P_{N_{2}} \Phi=r_{1, s}+\sum_{i=1}^{6} q_{i} P_{i}+q_{7} \Phi+\sum_{i=1}^{6} \sum_{l=\mathrm{i}}^{6} Q_{i l} P_{i} P_{l}+\sum_{i=1}^{6} Q_{i 7} P_{i} \Phi+Q_{77} \Phi^{2}
\end{aligned}
$$$$
q_{1}=-f_{1, S} \theta_{S}^{\odot^{2}} \theta_{S}^{\otimes^{4}} K_{C H_{3} O H}^{\odot} p_{1, S}-\left(1-\phi_{S}\right) \frac{k_{1}}{K_{P 1}} p_{1, S} \theta_{S}^{\odot} \theta_{S}^{\otimes 4}
$$$$
q_{2}=-f_{1, S} \theta_{s}^{\odot} \theta_{s}^{\otimes} K_{C O_{2}}^{\odot} p_{2, s}
$$$$
q_{3}=-f_{1, S} \theta_{s}^{\odot^{2}} \theta_{s}^{\otimes^{4}} K_{C O}^{\odot} p_{3, s}+\left(1-\phi_{s}\right) k_{1} p_{3, s} p_{4, s}{ }^{2} \theta_{s}^{\odot} \theta_{s}^{\otimes^{4}}
$$$$
q_{4}=-2 f_{1, S} \theta_{S}^{\odot} \theta_{S}^{\otimes^{5}} K_{H_{2}}{ }^{1 / 2} p_{4, s}{ }^{1 / 2}+2\left(1-\phi_{s}\right) k_{1} p_{3, s} p_{4, s}{ }^{2} \theta_{s}^{\odot} \theta_{s}^{\otimes}
$$$$
q_{7}=-\phi_{s} k_{1}\left(p_{3, s} p_{4, S}^{2}-\frac{1}{K_{P 1}} p_{1, s}\right) \theta_{s}^{\odot} \theta_{s}^{\otimes 4}
$$$$
Q_{11}=f_{1, S} \theta_{S}^{\odot^{3}} \theta_{S}^{\otimes^{4}} K_{C H_{3} O H}^{\odot}{ }^{2} p_{1, S}{ }^{2}+\left(1-\phi_{S}\right) \frac{k_{1}}{K_{P 1}} p_{1, s}{ }^{2} K_{C H_{3} O H}^{\odot} \theta_{S}^{\odot} \theta_{S}^{\otimes^{4}}
$$$$
Q_{22}=f_{1, S} \theta_{s}^{\odot^{3}} \theta_{s}^{\otimes}{ }^{4} K_{C O_{2}}{ }^{2} p_{2, s}{ }^{2}
$$$$
Q_{33}=f_{1, S} \theta_{s}^{\odot^{3}} \theta_{s}^{\otimes^{4}} K_{C O}^{\odot^{2}} p_{3, s}^{2}-\left(1-\phi_{s}\right) k_{1} p_{3, s}{ }^{2} p_{4, s}{ }^{2} K_{C O}^{\odot} \theta_{s}^{\odot^{2}} \theta_{s}^{\otimes^{4}}
$$

$Q_{44}=\left(1-\phi_{s}\right) k_{1} p_{3, s} p_{4, s}{ }^{2} \theta_{s}^{\odot} \theta_{s}^{\otimes}+\frac{1}{2} f_{1, S} \theta_{s}^{\odot} \theta_{s}^{\otimes^{5}} K_{H_{2}}{ }^{1 / 2} p_{4, s}{ }^{1 / 2}+\frac{5}{2} f_{1, S} \theta_{s}^{\odot} \theta_{s}^{\otimes^{6}} K_{H_{2}} p_{4, s}+$ $4\left(1-\phi_{s}\right) k_{1} p_{3, s} p_{4, S}{ }^{5 / 2} K_{H_{2}}{ }^{1 / 2} \theta_{s}^{\odot} \theta_{s}^{\otimes^{5}}$

$Q_{12}=2 f_{1, S} \theta_{s}^{\odot^{3}} \theta_{S}^{\otimes}{ }^{4} K_{C H_{3} O H}^{\odot} K_{C O_{2}}^{\odot} p_{1, s} p_{2, S}+\left(1-\phi_{S}\right) \frac{k_{1}}{K_{P 1}} p_{1, S} K_{C O_{2}}^{\odot} p_{2, s} \theta_{s}^{\odot^{2}} \theta_{s}^{\otimes^{4}}$

$$
Q_{13}=2 f_{1, S} \theta_{S}^{\odot^{3}} \theta_{S}^{\otimes}{ }^{4} K_{C H_{3} O H}^{\odot} K_{C O}^{\odot} p_{1, s} p_{3, S}+\left(1-\phi_{s}\right) \frac{k_{1}}{K_{P 1}} p_{1, S} K_{C O}^{\odot} p_{3, S} \theta_{S}^{\odot^{2}} \theta_{S}^{\otimes}-(1-
$$$$
\left.\phi_{s}\right) k_{1} p_{3, s} p_{4, s}^{2} K_{C H_{3} O H}^{\odot} p_{1, s} \theta_{s}^{\odot^{2}} \theta_{s}^{\otimes}
$$

$Q_{14}=-2\left(1-\phi_{S}\right) k_{1} p_{3, S} p_{4, S}{ }^{2} K_{C H_{3} O H}^{\odot} p_{1, S} \theta_{S}^{\odot^{2}} \theta_{S}^{\otimes}+2 f_{1, S} \theta_{S}^{\odot^{2}} \theta_{S}^{\otimes^{5}} K_{C H_{3} O H}^{\odot} p_{1, S} K_{H_{2}}{ }^{1 / 2} p_{4, S}{ }^{1 / 2}+$ $2\left(1-\phi_{s}\right) \frac{k_{1}}{K_{P 1}} p_{1, S} K_{H_{2}}{ }^{1 / 2} p_{4, S}{ }^{1 / 2} \theta_{S}^{\odot} \theta_{s}^{\otimes^{5}}$ 


$$
\begin{aligned}
& Q_{23}=2 f_{1, S} \theta_{S}^{\odot^{3}} \theta_{S}^{\otimes}{ }^{4} K_{C O_{2}}^{\odot} K_{C O}^{\odot} p_{2, s} p_{3, s}-\left(1-\phi_{s}\right) k_{1} p_{3, s} p_{4, s}{ }^{2} K_{C O_{2}}^{\odot} p_{4, S} \theta_{S}^{\odot}{ }^{2} \theta_{S}^{\otimes^{4}} \\
& Q_{24}=-2\left(1-\phi_{S}\right) k_{1} p_{3, S} p_{4, S}{ }^{2} K_{C O_{2}}^{\odot} p_{2, S} \theta_{S}^{\odot^{2}} \theta_{S}^{\otimes}+2 f_{1, S} \theta_{S}^{\odot^{2}} \theta_{S}^{\otimes^{5}} K_{C O_{2}}^{\odot} p_{2, S} K_{H_{2}}{ }^{1 / 2} p_{4, S}{ }^{1 / 2}
\end{aligned}
$$

$Q_{34}=$

$-2\left(1-\phi_{s}\right) k_{1} p_{3, s}{ }^{2} p_{4, s}{ }^{2} K_{C O}^{\odot} \theta_{s}^{\odot^{2}} \theta_{s}^{\otimes^{4}}+2\left(1-\phi_{s}\right) k_{1} p_{3, s} p_{4, s}{ }^{2} \theta_{s}^{\odot} \theta_{s}^{\otimes^{4}}+$

$2 f_{1, S} \theta_{S}^{\odot^{2}} \theta_{S}^{\otimes 5} K_{C O}^{\odot} p_{3, s} K_{H_{2}}{ }^{1 / 2} p_{4, s}{ }^{1 / 2}-2\left(1-\phi_{s}\right) k_{1} p_{3, s} p_{4, s}{ }^{5 / 2} K_{H_{2}}{ }^{1 / 2} \theta_{s}^{\odot} \theta_{s}^{\otimes^{5}}$

$Q_{17}=\phi_{s} k_{1}\left(p_{3, s} p_{4, S}^{2}-\frac{1}{K_{P 1}} p_{1, s}\right) K_{C H_{3} O H}^{\odot} p_{1, s} \theta_{S}^{\odot^{2}} \theta_{S}^{\otimes^{4}}+\phi_{s} \frac{k_{1}}{K_{P 1}} p_{1, s} \theta_{s}^{\odot} \theta_{s}^{\otimes^{4}}$

$Q_{27}=\phi_{s} k_{1}\left(p_{3, s} p_{4, s}^{2}-\frac{1}{K_{P 1}} p_{1, s}\right) K_{C O_{2}}^{\odot} p_{2, s} \theta_{s}^{\odot^{2}} \theta_{s}^{\otimes^{4}}$

$Q_{37}=\phi_{s} k_{1}\left(p_{3, s} p_{4, s}^{2}-\frac{1}{K_{P 1}} p_{1, s}\right) K_{C O}^{\odot} p_{3, s} \theta_{s}^{\odot^{2}} \theta_{S}^{\otimes^{4}}-\phi_{s} k_{1} p_{3, s} p_{4, s}^{2} \theta_{s}^{\odot} \theta_{s}^{\otimes^{4}}$

$Q_{47}=2 \phi_{s} k_{1}\left(p_{3, s} p_{4, s}{ }^{2}-\frac{1}{K_{P 1}} p_{1, s}\right) K_{H_{2}}{ }^{1 / 2} p_{4, s}{ }^{1 / 2} \theta_{s}^{\odot} \theta_{s}^{\otimes^{5}}-2 \phi_{s} k_{1} p_{3, s} p_{4, s}{ }^{2} \theta_{s}^{\odot} \theta_{s}^{\otimes^{4}}$

The following coefficients are equal to zero:

$q_{5}, q_{6}, Q_{15}, Q_{16}, Q_{25}, Q_{26}, Q_{55}, Q_{66}, Q_{77}, Q_{35}, Q_{36}, Q_{45}, Q_{46}, Q_{56}, Q_{57}, Q_{67}$

\section{Appendix C.2.Taylor series expansion of reaction rate of $\mathrm{CO}_{2}$ hydrogenations (Eq.12)}

The Taylor series expansion of the expression for the reaction rate of $\mathrm{CO}_{2}$ hydrogenation is given here.

$$
\begin{aligned}
& r_{2}=\phi^{2} k_{2}\left(p_{2} p_{4}^{2}-\frac{1}{K_{P 2}} \frac{p_{1} p_{5}}{p_{4}}\right) \theta^{* 2} \theta^{\otimes} \\
& f_{2, s}=\phi_{s}{ }^{2} k_{2}\left(p_{2, s} p_{4, s}{ }^{2}-\frac{1}{K_{P 2}} \frac{p_{1, s} p_{5, s}}{p_{4 s}}\right) \\
& r_{2} \approx r_{2, S}+\vartheta_{1} P_{C_{3} O H}+\vartheta_{2} P_{C_{2}}+\vartheta_{3} P_{C O}+\vartheta_{4} P_{H_{2}}+\vartheta_{5} P_{H_{2} O}+\vartheta_{6} P_{N_{2}}+\vartheta_{7} \Phi+U_{11} P_{C_{3} O H}{ }^{2} \\
& +U_{22} P_{\mathrm{CO}_{2}}{ }^{2}+U_{33} P_{\mathrm{CO}}{ }^{2}+U_{44}{P_{H_{2}}}^{2}+U_{55} P_{\mathrm{H}_{2} \mathrm{O}}{ }^{2}+U_{66}{P_{N_{2}}}^{2}+U_{77} \Phi^{2} \\
& +U_{12} P_{\mathrm{CH}_{3} \mathrm{OH}} P_{\mathrm{CO}_{2}}+U_{13} P_{\mathrm{CH}_{3} \mathrm{OH}} P_{\mathrm{CO}}+U_{14} P_{\mathrm{CH}_{3} \mathrm{OH}} P_{\mathrm{H}_{2}}+U_{15} P_{\mathrm{CH}_{3} \mathrm{OH}} P_{\mathrm{H}_{2} \mathrm{O}} \\
& +U_{16} P_{C_{3} \mathrm{OH}_{2}} P_{\mathrm{N}_{2}}+U_{23} P_{\mathrm{CO}_{2}} P_{\mathrm{CO}}+U_{24} P_{\mathrm{CO}_{2}} P_{\mathrm{H}_{2}}+U_{25} P_{\mathrm{CO}_{2}} P_{\mathrm{H}_{2} \mathrm{O}}+U_{26} P_{\mathrm{CO}_{2}} P_{N_{2}} \\
& +U_{34} P_{C O} P_{H_{2}}+U_{35} P_{C O} P_{H_{2} O}+U_{36} P_{C O} P_{N_{2}}+U_{45} P_{H_{2}} P_{H_{2} O}+U_{46} P_{H_{2}} P_{N_{2}} \\
& +U_{56} P_{\mathrm{H}_{2} \mathrm{O}} P_{\mathrm{N}_{2}}+U_{17} P_{\mathrm{CH}_{3} \mathrm{OH}} \Phi+U_{27} P_{\mathrm{CO}_{2}} \Phi+U_{37} P_{\mathrm{CO}} \Phi+U_{47} P_{\mathrm{H}_{2}} \Phi+U_{57} P_{\mathrm{H}_{2} \mathrm{O}} \Phi \\
& +U_{67} P_{N_{2}} \Phi=r_{2, s}+\sum_{i=1}^{6} \vartheta_{i} P_{i}+\vartheta_{7} \Phi+\sum_{i=1}^{6} \sum_{l=\mathrm{i}}^{6} U_{i l} P_{i} P_{l}+\sum_{i=1}^{6} U_{i 7} P_{i} \Phi+U_{77} \Phi^{2}
\end{aligned}
$$




$$
\begin{aligned}
& \varepsilon=\frac{K_{O} K_{H_{2} O} \mathrm{O}}{K_{H_{2}}} \frac{p_{5, s}}{p_{4, S}} \\
& \epsilon=\frac{1}{K_{P 2}} \frac{p_{1, s} p_{5, s}}{p_{4, s}} \\
& \vartheta_{1}=-2 f_{2, S} \theta_{s}^{* 3} \theta_{s}^{\otimes}{ }^{4} K_{C H_{3} O H}^{*} p_{1, s}-\phi_{s}{ }^{2} k_{2} \beta \theta_{s}^{* 2} \theta_{s}^{\otimes} \\
& \vartheta_{2}=-2 f_{2, s} \theta_{s}^{* 3} \theta_{s}^{\otimes} K_{C O_{2}}^{*} p_{2, s}+\phi_{s}{ }^{2} k_{2} p_{2, s} p_{4, s}{ }^{2} \theta_{s}^{* 2} \theta_{s}^{\otimes} \\
& \vartheta_{4}=2 f_{2, s} \theta_{s}^{* 3} \theta_{s}^{\otimes^{4}} \varepsilon-2 f_{2, s} \theta_{s}^{* 2} \theta_{s}^{\otimes 5} K_{H_{2}}{ }^{1 / 2} p_{4, s}{ }^{1 / 2}+\phi_{s}{ }^{2} k_{2}\left(2 p_{2, s} p_{4, s}{ }^{2}+\epsilon\right) \theta_{s}^{* 2} \theta_{s}^{\otimes} \\
& \vartheta_{5}=-2 f_{2, s} \theta_{s}^{* 3} \theta_{s}^{\otimes}\left(K_{H_{2} o} p_{5, s}+\varepsilon\right)-\phi_{s}{ }^{2} k_{2} \epsilon \theta_{s}^{* 2} \theta_{s}^{\otimes} \\
& \vartheta_{7}=2 f_{2, s} \theta_{s}^{* 2} \theta_{s}^{\otimes} \\
& U_{11}=3 f_{2, s} \theta_{s}^{* 4} \theta_{S}^{\otimes}{ }^{4} K_{C H_{3} O H}^{*}{ }^{2} p_{1, s}^{2}+2 K_{C H_{3} O H}^{*} p_{1, s} \phi_{s}^{2} k_{2} \epsilon \theta_{s}^{* 3} \theta_{s}^{\otimes} \\
& U_{22}=3 f_{2, s} \theta_{s}^{* 4} \theta_{s}^{\otimes}{ }^{4} K_{C O_{2}}^{*} p_{2, s}{ }^{2}-2 K_{C O_{2}}^{*} \phi_{s}{ }^{2} k_{2} p_{2, s}{ }^{2} p_{4, s}{ }^{2} \theta_{s}^{* 3} \theta_{s}^{\otimes} \\
& U_{44}=3 f_{2, s} \theta_{s}^{* 4} \theta_{s}^{\otimes}{ }^{4} \varepsilon^{2}-2 f_{2, S} \theta_{s}^{* 3} \theta_{s}^{\otimes}{ }^{4} \varepsilon-4 f_{2, s} \theta_{s}^{* 3} \theta_{s}^{\otimes 5} K_{H_{2}}{ }^{1 / 2} p_{4, s}{ }^{1 / 2} \alpha+\frac{5}{2} f_{2, s} \theta_{s}^{* 2} \theta_{s}^{\otimes}{ }^{6} K_{H_{2}} p_{4, s}+ \\
& \frac{1}{2} f_{2, s} \theta_{s}^{* 2} \theta_{s}^{\otimes 5} K_{H_{2}}{ }^{1 / 2} p_{4, s}{ }^{1 / 2}+2 \varepsilon \phi_{s}{ }^{2} k_{2}\left(2 p_{2, s} p_{4, s}{ }^{2}+\epsilon\right) \theta_{s}^{* 3} \theta_{s}^{\otimes}- \\
& 2 K_{H_{2}}{ }^{1 / 2} p_{4, s}{ }^{1 / 2} \phi_{s}{ }^{2} k_{2}\left(2 p_{2, s} p_{4, s}{ }^{2}+\epsilon\right) \theta_{s}^{* 2} \theta_{s}^{\otimes 5}+f_{2, s} \theta_{s}^{* 2} \theta_{s}^{\otimes^{4}} \\
& U_{55}=3 f_{2, s} \theta_{s}^{* 4} \theta_{s}^{\otimes^{4}}\left(K_{H_{2} O} p_{5, s}+\varepsilon\right)^{2}+2\left(K_{H_{2} O} p_{5, s}+\varepsilon\right) \phi_{s}{ }^{2} k_{2} \beta \theta_{s}^{* 3} \theta_{s}^{\otimes^{4}} \\
& U_{77}=f_{2, s} \theta_{s}^{* 2} \theta_{s}^{\otimes} \\
& U_{12}= \\
& 6 f_{2, s} \theta_{s}^{* 4} \theta_{s}^{\otimes} K_{C H_{3} O H}^{*} K_{C O_{2}}^{*} p_{1, s} p_{2, s}-2 K_{C H_{3} O H}^{*} p_{1, s} \phi_{s}{ }^{2} k_{2} p_{2, s} p_{4, s}{ }^{2} \theta_{s}^{* 3} \theta_{s}^{\otimes}+ \\
& 2 K_{\mathrm{CO}_{2}}^{*} p_{2, s} \phi_{s}^{2} k_{2} \beta \theta_{s}^{* 3} \theta_{s}^{\otimes^{4}} \\
& U_{14}= \\
& -6 f_{2, s} \theta_{s}^{* 4} \theta_{S}^{\otimes} K_{C H_{3} O H}^{*} p_{1, s} \varepsilon+4 f_{2, s} \theta_{S}^{* 3} \theta_{s}^{\otimes} K_{C H_{3} O H}^{*} p_{1, s} K_{H_{2}}{ }^{1 / 2} p_{4, s}{ }^{1 / 2}- \\
& 2 K_{C H_{3} O H}^{*} p_{1, s} \phi_{s}{ }^{2} k_{2}\left(2 p_{2, s} p_{4, s}{ }^{2}+\epsilon\right) \theta_{s}^{* 3} \theta_{s}^{\otimes^{4}}-2 \varepsilon \phi_{s}{ }^{2} k_{2} \beta \theta_{s}^{* 3} \theta_{s}^{\otimes^{4}}+ \\
& 2 K_{H_{2}}{ }^{1 / 2} p_{4, s}{ }^{1 / 2} \phi_{s}{ }^{2} k_{2} \epsilon \theta_{s}^{* 2} \theta_{s}^{\otimes^{5}}+\phi_{s}{ }^{2} k_{2} \epsilon \theta_{s}^{* 2} \theta_{s}^{\otimes^{4}} \\
& U_{15}=6 f_{2, s} \theta_{s}^{* 4} \theta_{S}^{\otimes} K_{C H_{3} O H}^{*} p_{1, s}\left(K_{H_{2} O} p_{5, S}+\varepsilon\right)+2\left(K_{H_{2} O} p_{5, S}+\varepsilon\right) \phi_{s}{ }^{2} k_{2} \epsilon \theta_{s}^{* 3} \theta_{S}^{\otimes}+ \\
& 2 K_{C H_{3} O H}^{*} p_{1, s} \phi_{s}{ }^{2} k_{2} \epsilon \theta_{s}^{* 3} \theta_{s}^{\otimes^{4}}-\phi_{s}{ }^{2} k_{2} \epsilon \theta_{s}^{*} \theta_{s}^{\otimes^{4}} \\
& U_{24}= \\
& -6 f_{2, s} \theta_{s}^{* 4} \theta_{s}^{\otimes^{4}} K_{C O_{2}}^{*} p_{2, s} \varepsilon+4 f_{2, s} \theta_{s}^{* 3} \theta_{s}^{\otimes^{5}} K_{C O_{2}}^{*} p_{2, s} K_{H_{2}}{ }^{1 / 2} p_{4, s}{ }^{1 / 2}+2 \varepsilon \phi_{s}{ }^{2} k_{2} p_{2, s} p_{4, s}{ }^{2} \theta_{s}^{* 3} \theta_{s}^{\otimes}-
\end{aligned}
$$




$$
\begin{aligned}
& 2 K_{H_{2}}{ }^{1 / 2} \phi_{s}{ }^{2} k_{2} p_{2, s} p_{4, s}{ }^{5 / 2} \theta_{s}^{* 2} \theta_{s}^{\otimes}-2 K_{C O_{2}}^{*} p_{2, s} \phi_{s}{ }^{2} k_{2}\left(2 p_{2, s} p_{4, s}{ }^{2}+\epsilon\right) \theta_{s}^{* 3} \theta_{s}^{\otimes}+ \\
& 2 \phi_{s}^{2} k_{2} p_{2, s} p_{4, s}^{2} \theta_{s}^{* 2} \theta_{s}^{\otimes} \\
& U_{25}=6 f_{2, s} \theta_{s}^{* 4} \theta_{s}^{\otimes} K_{C O_{2}}^{*} p_{2, s}\left(K_{H_{2} O} p_{5, s}+\varepsilon\right)-2 \phi_{s}{ }^{2} k_{2} p_{2, s} p_{4, s}{ }^{2}\left(K_{H_{2} O} p_{5, s}+\varepsilon\right) \theta_{s}^{* 3} \theta_{s}^{\otimes}+ \\
& 2 K_{C O_{2}}^{*} p_{2, s} \phi_{s}^{2} k_{2} \in \theta_{s}^{* 3} \theta_{s}^{\otimes} \\
& U_{45}=-6 f_{2, s} \theta_{s}^{* 4} \theta_{s}^{\otimes}\left(K_{H_{2} o} p_{5, s}+\varepsilon\right) \varepsilon+2 f_{2, s} \theta_{s}^{* 3} \theta_{s}^{\otimes^{4}}{ }_{\varepsilon}+4 f_{2, s} \theta_{s}^{* 3} \theta_{s}^{\otimes^{5}} K_{H_{2}}{ }^{1 / 2} p_{4, s}{ }^{1 / 2}\left(K_{H_{2} o} p_{5, s}+\right. \\
& \varepsilon)-2 \phi_{s}{ }^{2} k_{2}\left(2 p_{2, s} p_{4, s}{ }^{2}+\epsilon\right)\left(K_{H_{2} O} p_{5, s}+\varepsilon\right) \theta_{s}^{* 3} \theta_{s}^{\otimes}-2 \varepsilon \phi_{s}{ }^{2} k_{2} \epsilon \theta_{s}^{* 3} \theta_{s}^{\otimes}+ \\
& 2 K_{H_{2}}{ }^{1 / 2} p_{4, s}{ }^{1 / 2} \phi_{s}{ }^{2} k_{2} \epsilon \theta_{s}^{* 2} \theta_{s}^{\otimes^{5}}+\phi_{s}{ }^{2} k_{2} \epsilon \theta_{s}^{*^{2}} \theta_{s}^{\otimes^{4}} \\
& U_{17}=-4 f_{2, S} \theta_{s}^{* 3} \theta_{s}^{\otimes}{ }^{4} K_{C H_{3} O H}^{*} p_{1, S}-2 \phi_{s}{ }^{2} k_{2} \epsilon \theta_{s}^{* 2} \theta_{s}^{\otimes} \\
& U_{27}=-4 f_{2, s} \theta_{s}^{* 3} \theta_{s}^{\otimes} K_{C O_{2}}^{*} p_{2, s}+2 \phi_{s}{ }^{2} k_{2} p_{2, s} p_{4, s}{ }^{2} \theta_{s}^{* 2} \theta_{s}^{\otimes} \\
& U_{47}=4 f_{2, s} \theta_{s}^{* 3} \theta_{s}^{\otimes^{4}}{ }_{\varepsilon}-4 f_{2, s} \theta_{s}^{* 2} \theta_{s}^{\otimes^{5}} K_{H_{2}}{ }^{1 / 2} p_{4, s}{ }^{1 / 2}+2 \phi_{s}{ }^{2} k_{2}\left(2 p_{2, s} p_{4, s}{ }^{2}+\epsilon\right) \theta_{s}^{* 2} \theta_{s}^{\otimes^{4}}
\end{aligned}
$$$$
U_{57}=-4 f_{2, s} \theta_{s}^{* 3} \theta_{s}^{\otimes}\left(K_{H_{2} O} p_{5, s}+\varepsilon\right)-2 \phi_{s}{ }^{2} k_{2} \epsilon \theta_{s}^{* 2} \theta_{s}^{\otimes^{4}}
$$

The following coefficients are equal to zero:

$\vartheta_{3,} \vartheta_{6}, U_{33,}, U_{66}, U_{13}, U_{16}, U_{23}, U_{26}, U_{34}, U_{35}, U_{36}, U_{46}, U_{56}, U_{37}, U_{67}$

\section{Appendix C.3.Taylor series expansion of reaction rate of RWGS reactions (Eq.13)}

Taylor series expansion of the expression for the reaction rate of reverse water-gas shift reaction (Eq. 13) is given below.

$$
\begin{aligned}
& r_{3}=\phi(1-\phi)^{-1} k_{3}\left(p_{2}-\frac{1}{K_{P 3}} \frac{p_{3} p_{5}}{p_{4}}\right) \theta^{*} \theta^{\odot} \\
& f_{S}=\phi_{S}\left(1-\phi_{S}\right)^{-1} k_{3}\left(p_{2, S}-\frac{1}{K_{P 3}} \frac{p_{3, S} p_{5, S}}{p_{4, S}}\right) \\
& r_{3} \approx r_{3, S}+s_{1} P_{C H_{3} O H}+s_{2} P_{C O_{2}}+s_{3} P_{C O}+s_{4} P_{H_{2}}+S_{5} P_{H_{2} O}+s_{6} P_{N_{2}}++S_{7} \Phi+S_{11} P_{C H_{3} O H}{ }^{2} \\
&+S_{22} P_{C O_{2}}{ }^{2}+S_{33} P_{C O}{ }^{2}+S_{44} P_{H_{2}}{ }^{2}+S_{55} P_{H_{2} O}{ }^{2}+S_{66} P_{N_{2}}{ }^{2}+S_{77} \Phi^{2} \\
&+S_{12} P_{C H_{3} O H} P_{C O_{2}}+S_{13} P_{C H_{3} O H} P_{C O}+S_{14} P_{C H_{3} O H} P_{H_{2}}+S_{15} P_{C H_{3} O H} P_{H_{2} O} \\
&+S_{16} P_{C H_{3} O H} P_{N_{2}}+S_{23} P_{C O_{2}} P_{C O}+S_{24} P_{C O_{2}} P_{H_{2}}+S_{25} P_{C O_{2}} P_{H_{2} O}+S_{26} P_{C O_{2}} P_{N_{2}} \\
&+S_{34} P_{C O} P_{H_{2}}+S_{35} P_{C O} P_{H_{2} O}+S_{36} P_{C O} P_{N_{2}}+S_{45} P_{H_{2}} P_{H_{2} O}+S_{46} P_{H_{2}} P_{N_{2}} \\
&+S_{56} P_{H_{2} O} P_{N_{2}}+S_{17} P_{C H_{3} O H} \Phi+S_{27} P_{C O_{2}} \Phi+S_{37} P_{C O} \Phi+S_{47} P_{H_{2}} \Phi+S_{57} P_{H_{2} O} \Phi \\
&+S_{67} P_{N_{2}} \Phi=r_{3, S}+\sum_{i=1}^{6} s_{i} P_{i}+s_{7} \Phi+\sum_{i=1}^{6} \sum_{l=i}^{6} S_{i l} P_{i} P_{l}+\sum_{i=1}^{6} S_{i 7} P_{i} \Phi+S_{77} \Phi^{2}
\end{aligned}
$$




$$
\begin{aligned}
& \zeta=\frac{1}{K_{P 3}} \frac{p_{3, s} p_{5, S}}{p_{4, S}} \\
& s_{1}=-f_{3, s} \theta_{s}^{* 2} \theta_{s}^{\odot} K_{C H_{3} O H}^{*} p_{1, s}-f_{3, S} \theta_{s}^{*} \theta_{S}^{\odot}{ }^{2} K_{C H_{3} O H}^{\odot} p_{1, S} \\
& s_{2}=-f_{3, s} \theta_{s}^{* 2} \theta_{s}^{\odot} K_{C O_{2}}^{*} p_{2, s}-f_{3, s} \theta_{s}^{*} \theta_{s}^{\odot^{2}} K_{C O_{2}}^{\odot} p_{2, s}+\phi_{s}\left(1-\phi_{s}\right)^{-1} k_{3} p_{2, s} \theta_{s}^{*} \theta_{s}^{\odot} \\
& s_{3}=-f_{3, s} \theta_{s}^{*} \theta_{s}^{\odot^{2}} K_{C O}^{\odot} p_{3, s}-\phi_{s}\left(1-\phi_{s}\right)^{-1} k_{3} \zeta \theta_{s}^{*} \theta_{s}^{\odot} \\
& s_{4}=f_{3, s} \theta_{s}^{* 2} \theta_{s}^{\odot} \varepsilon+\phi_{s}\left(1-\phi_{s}\right)^{-1} k_{3} \zeta \theta_{s}^{*} \theta_{s}^{\odot} \\
& s_{5}=-f_{3, s} \theta_{s}^{* 2} \theta_{s}^{\odot}\left(K_{H_{2} O} p_{5, s}+\varepsilon\right)-\phi_{s}\left(1-\phi_{s}\right)^{-1} k_{3} \zeta \theta_{s}^{*} \theta_{s}^{\odot} \\
& s_{7}=\phi_{s}\left(1-\phi_{s}\right)^{-2} k_{3}\left(p_{2, s}-\zeta\right) \theta_{s}^{*} \theta_{s}^{\odot} \\
& S_{11}=f_{3, S} \theta_{S}^{*} \theta_{s}^{\odot} p_{1, S}{ }^{2}\left(\theta_{s}^{* 2} K_{C H_{3} O H}^{*}+\theta_{S}{ }^{2} K_{C H_{3} O H}{ }^{2}+\theta_{s}^{*} \theta_{S}^{\odot} K_{C H_{3} O H}^{*} K_{C H_{3} O H}^{\odot}\right) \\
& S_{22}= \\
& f_{3, s} \theta_{s}^{*} \theta_{s}^{\odot} p_{2, s}{ }^{2}\left(\theta_{s}^{* 2} K_{C O_{2}}^{*}{ }^{2}+\theta_{S}^{\odot^{2}} K_{C O_{2}}{ }^{2}+\theta_{s}^{*} \theta_{s}^{\odot} K_{C_{2}}^{*} K_{C O_{2}}^{\odot}\right)- \\
& \phi_{s}\left(1-\phi_{s}\right)^{-1} k_{3} p_{2, s}{ }^{2} \theta_{s}^{*} \theta_{S}^{\odot}\left(K_{C O_{2}}^{*} \theta_{s}^{*}+K_{C O_{2}}^{\odot} \theta_{S}^{\odot}\right) \\
& S_{33}=f_{3, s} \theta_{s}^{*} \theta_{s}^{\odot^{3}} K_{C O}^{\odot^{2}} p_{3, s}^{2}+K_{C O}^{\odot} p_{3, s} \phi_{s}\left(1-\phi_{s}\right)^{-1} k_{3} \zeta \theta_{s}^{*} \theta_{s}^{\odot} \\
& S_{44}=f_{3, s} \theta_{s}^{* 2} \theta_{s}^{\odot} \epsilon\left(\varepsilon \theta_{s}^{*}-1\right)+\varepsilon \phi_{s}\left(1-\phi_{s}\right)^{-1} k_{3} \zeta \theta_{s}^{* 2} \theta_{s}^{\odot}-\phi_{s}\left(1-\phi_{s}\right)^{-1} k_{3} \zeta \theta_{s}^{*} \theta_{s}^{\odot} \\
& S_{55}=f_{3, s} \theta_{s}^{* 3} \theta_{s}^{\odot}\left(K_{H_{2} O} p_{5, s}+\varepsilon\right)^{2}+\left(K_{H_{2} O} p_{5, s}+\varepsilon\right) \phi_{s}\left(1-\phi_{s}\right)^{-1} k_{3} \zeta \theta_{s}^{* 2} \theta_{s}^{\odot} \\
& S_{77}=\phi_{s}^{2}\left(1-\phi_{s}\right)^{-3} k_{3}\left(p_{2, s}-\zeta\right) \theta_{s}^{*} \theta_{s}^{\odot} \\
& S_{12}=f_{3, s} \theta_{s}^{*} \theta_{s}^{\odot} p_{1, s} p_{2, s}\left(2 \theta_{s}^{* 2} K_{\mathrm{CH}_{3} \mathrm{OH}}^{*} K_{\mathrm{CO}_{2}}^{*}+2 \theta_{S}^{\odot}{ }^{2} K_{\mathrm{CH}_{3} \mathrm{OH}}^{\odot} K_{\mathrm{CO}_{2}}^{\odot}+\theta_{s}^{*} \theta_{S}^{\odot} K_{\mathrm{CH}_{3} \mathrm{OH}}^{*} K_{\mathrm{CO}_{2}}^{\odot}+\right. \\
& \left.\theta_{S}^{*} \theta_{s}^{\odot} K_{C H_{3} O H}^{\odot} K_{C O_{2}}^{*}\right)-p_{1, s} \theta_{s}^{*} \theta_{s}^{\odot} \phi_{s}\left(1-\phi_{s}\right)^{-1} k_{3} p_{2, S}\left(K_{C H_{3} O H}^{*} \theta_{s}^{*}+K_{C H_{3} O H}^{\odot} \theta_{s}^{\odot}\right) \\
& S_{13}=f_{3, s} \theta_{s}^{*} \theta_{s}^{\odot} p_{1, s} p_{3, s}\left(\theta_{s}^{*} \theta_{s}^{\odot} K_{C H_{3} O H}^{*} K_{C O}^{\odot}+2 \theta_{s}^{\odot}{ }^{2} K_{C H_{3} O H}^{\odot} K_{C O}^{\odot}\right)+p_{1, s} \theta_{s}^{*} \theta_{s}^{\odot} \phi_{s}(1- \\
& \left.\phi_{S}\right)^{-1} k_{3} \zeta\left(K_{\mathrm{CH}_{3} \mathrm{OH}}^{*} \theta_{S}^{*}+K_{\mathrm{CH}_{3} \mathrm{OH}}^{\odot} \theta_{S}^{\odot}\right) \\
& S_{14}=-f_{3, s} \theta_{s}^{*} \theta_{s}^{\odot} p_{1, s} \varepsilon\left(2 \theta_{s}^{* 2} K_{C H_{3} O H}^{*}+\theta_{s}^{*} \theta_{s}^{\odot} K_{C H_{3} O H}^{\odot}\right)-p_{1, s} \theta_{S}^{*} \theta_{S}^{\odot} \phi_{S}\left(1-\phi_{s}\right)^{-1} k_{3} \zeta\left(K_{1}^{*} \theta_{s}^{*}+\right. \\
& \left.\mathrm{K}_{\mathrm{CH}_{3} \mathrm{OH}}^{\odot} \theta_{S}^{\odot}\right) \\
& S_{15}=f_{3, S} \theta_{S}^{*} \theta_{S}^{\odot} p_{1, S}\left(K_{H_{2} O} p_{5, S}+\varepsilon\right)\left(2 \theta_{S}^{* 2} K_{C H_{3} O H}^{*}+\theta_{S}^{*} \theta_{S}^{\odot} K_{C H_{3} O H}^{\odot}\right)+p_{1, S} \theta_{S}^{*} \theta_{S}^{\odot} \phi_{S}(1- \\
& \left.\phi_{S}\right)^{-1} k_{3} \zeta\left(K_{\mathrm{CH}_{3} \mathrm{OH}}^{*} \theta_{S}^{*}+K_{\mathrm{CH}_{3} \mathrm{OH}}^{\odot} \theta_{S}^{\odot}\right) \\
& S_{23}= \\
& f_{3, s} \theta_{s}^{*} \theta_{s}^{\odot} p_{2, s} p_{3, s}\left(\theta_{s}^{*} \theta_{s}^{\odot} K_{C O_{2}}^{*} K_{C O}^{\odot}+2 \theta_{s}^{\odot^{2}} K_{C O_{2}}^{\odot} K_{C O}^{\odot}\right)+p_{2, s} \theta_{s}^{*} \theta_{s}^{\odot} \phi_{s}\left(1-\phi_{s}\right)^{-1} k_{3} \zeta\left(\theta_{s}^{*} K_{C O_{2}}^{*}+\right. \\
& \left.\theta_{s}^{\odot} K_{C O_{2}}^{\odot}\right)-K_{C O}^{\odot} p_{C O, s} \phi_{S}\left(1-\phi_{s}\right)^{-1} k_{3} p_{2, s} \theta_{s}^{*} \theta_{S}^{\odot}
\end{aligned}
$$




$$
\begin{aligned}
& S_{24}=-f_{3, s} \theta_{s}^{*} \theta_{s}^{\odot} \varepsilon p_{2, s}\left(2 \theta_{s}^{* 2} K_{C O_{2}}^{*}+\theta_{s}^{*} \theta_{s}^{\odot} K_{C O_{2}}^{\odot}\right)-p_{2, s} \theta_{s}^{*} \theta_{s}^{\odot} \phi_{s}\left(1-\phi_{s}\right)^{-1} k_{3} \zeta\left(\theta_{s}^{*} K_{C O_{2}}^{*}+\right. \\
& \left.\theta_{s}^{\odot} K_{C O_{2}}^{\odot}\right)+\varepsilon \phi_{s}\left(1-\phi_{s}\right)^{-1} k_{3} p_{2, s} \theta_{s}^{* 2} \theta_{s}^{\odot} \\
& S_{25}= \\
& f_{3, s} \theta_{s}^{*} \theta_{s}^{\odot}\left(K_{H_{2} O} p_{5, s}+\varepsilon\right) p_{2, s}\left(2 \theta_{s}^{* 2} K_{C O_{2}}^{*}+\theta_{s}^{*} \theta_{s}^{\odot} K_{C O_{2}}^{\odot}\right)+p_{2, s} \theta_{s}^{*} \theta_{s}^{\odot} \phi_{s}\left(1-\phi_{s}\right)^{-1} k_{3} \zeta\left(\theta_{S}^{*} K_{C O_{2}}^{*}+\right. \\
& \left.\theta_{s}^{\odot} K_{\mathrm{CO}_{2}}^{\odot}\right)-\left(K_{\mathrm{H}_{2} \mathrm{O}} p_{5, s}+\varepsilon\right) \phi_{s}\left(1-\phi_{s}\right)^{-1} k_{3} p_{2, s} \theta_{s}^{* 2} \theta_{s}^{\odot} \\
& S_{34}=-f_{3, S} \theta_{s}^{* 2} \theta_{S}^{\odot^{2}} K_{C O}^{\odot} p_{3, S} \varepsilon-\theta_{s}^{*} \theta_{s}^{\odot} \phi_{S}\left(1-\phi_{s}\right)^{-1} k_{3} \zeta\left(\theta_{S}^{*} \varepsilon+\theta_{S}^{\odot} K_{C O}^{\odot} p_{3, S}\right)+\phi_{s}(1- \\
& \left.\phi_{s}\right)^{-1} k_{3} \zeta \theta_{s}^{*} \theta_{s}^{\odot} \\
& S_{35}=f_{3, s} \theta_{s}^{* 2} \theta_{s}^{\odot^{2}} K_{C O}^{\odot} p_{3, s}\left(K_{H_{2} O} p_{5, s}+\varepsilon\right)+\theta_{s}^{*} \theta_{s}^{\odot} \phi_{s}\left(1-\phi_{s}\right)^{-1} k_{3} \zeta\left[\theta_{s}^{*}\left(K_{H_{2} O} p_{5, s}+\varepsilon\right)+\right. \\
& \left.\theta_{s}^{\odot} K_{C O}^{\odot} p_{3, s}\right]-\phi_{s}\left(1-\phi_{s}\right)^{-1} k_{3} \zeta \theta_{S}^{*} \theta_{s}^{\odot} \\
& S_{45}=f_{3, s} \theta_{s}^{* 2} \theta_{s}^{\odot} \varepsilon\left[1-2 \theta_{s}^{*}\left(K_{H_{2} O} p_{5, s}+\varepsilon\right)\right]-\theta_{s}^{* 2} \theta_{s}^{\odot} \phi_{s}\left(1-\phi_{s}\right)^{-1} k_{3} \zeta\left(2 \varepsilon+K_{H_{2} O} p_{5, s}\right)+ \\
& \phi_{s}\left(1-\phi_{s}\right)^{-1} k_{3} \zeta \theta_{s}^{*} \theta_{s}^{\odot} \\
& S_{17}=-\left(1-\phi_{S}\right)^{-1} f_{3, S} \theta_{S}^{*} \theta_{S}^{\odot} p_{1, S}\left(K_{C H_{3} O H}^{*} \theta_{S}^{*}+K_{C_{3} O H}^{\odot} \theta_{S}^{\odot}\right) \\
& S_{27}=-\left(1-\phi_{s}\right)^{-1} f_{3, s} \theta_{s}^{*} \theta_{s}^{\odot} p_{2, s}\left(\theta_{s}^{*} K_{C O_{2}}^{*}+\theta_{s}^{\odot} K_{C O_{2}}^{\odot}\right)+\phi_{s}\left(1-\phi_{s}\right)^{-2} k_{3} p_{2, s} \theta_{s}^{*} \theta_{s}^{\odot}
\end{aligned}
$$$$
S_{37}=-\left(1-\phi_{s}\right)^{-1} f_{3, s} \theta_{s}^{*} \theta_{s}^{\odot}{ }^{2} K_{C O}^{\odot} p_{3, s}-\phi_{s}\left(1-\phi_{s}\right)^{-2} k_{3} \zeta \theta_{s}^{*} \theta_{s}^{\odot}
$$$$
S_{47}=\left(1-\phi_{s}\right)^{-1} f_{3, s} \theta_{s}^{* 2} \theta_{s}^{\odot} \varepsilon+\phi_{s}\left(1-\phi_{s}\right)^{-2} k_{3} \zeta \theta_{s}^{*} \theta_{s}^{\odot}
$$$$
S_{57}=-\left(1-\phi_{s}\right)^{-1} f_{3, s} \theta_{s}^{* 2} \theta_{s}^{\odot}\left(K_{H_{2} O} p_{5, s}+\varepsilon\right)-\phi_{s}\left(1-\phi_{s}\right)^{-2} k_{3} \zeta \theta_{s}^{*} \theta_{s}^{\odot}
$$

The following coefficients are equal to zero:

$s_{6}, S_{16}, S_{26}, S_{36}, S_{46}, S_{56}, S_{66}, S_{76}$

\section{Appendix D. The auxiliary parameters in Eq. (25) of dimensionless mathematical model}

The auxiliary parameters used in Eq. (25) of dimensionless mathematical model, which describes the catalyst dynamic, are defined as follows:

$$
\begin{gathered}
E_{1}=k_{1}^{+} \frac{p_{3, s}}{p_{t o t}} \frac{V_{G}}{\dot{V}_{0, s}} \\
E_{2}=\frac{k_{1}^{+}}{K_{1}} \frac{p_{2, s}}{p_{t o t}} \frac{V_{G}}{\dot{V}_{0, s}} \\
E_{3}=k_{2}^{+} \frac{p_{4, s}}{p_{t o t}} \frac{V_{G}}{\dot{V}_{0, s}} \\
E_{4}=\frac{k_{2}^{+}}{K_{2}} \frac{p_{5, s}}{p_{t o t}} \frac{V_{G}}{\dot{V}_{0, S}}
\end{gathered}
$$




\section{Appendix E - Coefficients used in matrix equation for derivation of first order $G$ FRFs}

The coefficients $\alpha_{i l}$ are defined in the following way:

$\alpha_{i l}=m_{c a t} q_{s a t} \frac{R T}{V_{G}} \frac{p_{l, s}}{p_{i, s}}\left(\frac{\partial \theta_{i}}{\partial p_{l}}\right) j \omega-\frac{R T}{p_{i, s} \dot{V}_{0, s}} m_{c a t}\left(v_{i, 1} q_{l}+v_{i, 2} \vartheta_{l}+v_{i, 3} s_{l}\right), i \neq l, i, l=1, \ldots, 5$

$\alpha_{i i}=\left(1+m_{c a t} q_{s a t} \frac{R T}{V_{G}}\left(\frac{\partial \theta_{i}}{\partial p_{i}}\right)\right) j \omega+\frac{\dot{V}_{s}}{\dot{V}_{0, s}}-\frac{R T}{p_{i, s} \dot{V}_{0, s}} m_{c a t}\left(v_{i, 1} q_{i}+v_{i, 2} \vartheta_{i}+v_{i, 3} s_{i}\right), i=1, \ldots, 5$

$\alpha_{i 6}=-\frac{R T}{p_{i, s} \dot{V}_{0, s}} m_{c a t}\left(v_{i, 1} q_{l}+v_{i, 2} \vartheta_{l}+v_{i, 3} s_{l}\right), \quad i=1, \ldots, 5$

$\alpha_{i 7}=\frac{\dot{V}_{s}}{\dot{V}_{0, s}}, i=1, \ldots, 5$

$\alpha_{62}=E_{2}$

$\alpha_{63}=-\frac{\left(\phi_{\max }-\phi_{s}\right)}{\phi_{s}} E_{1}$

$\alpha_{64}=-\frac{\left(\phi_{\max }-\phi_{s}\right)}{\phi_{s}} E_{3}$

$\alpha_{65}=E_{4}$

$\alpha_{66}=j \omega+E_{1}+E_{2}+E_{3}+E_{4}$

The coefficients $\alpha_{61}, \alpha_{67}$ are equal to zero $\left(\alpha_{61}=\alpha_{67}=0\right)$.

$\alpha_{7 i}=m_{c a t} q_{s a t} \frac{\dot{V}_{0, s}}{V_{G}} p_{i, s} \sum_{l=1}^{5} \frac{\partial \theta_{l}}{\partial p_{i}} j \omega-m_{c a t}\left(-2 q_{i}-2 \vartheta_{i}\right), i=1, \ldots, 5$

$\alpha_{76}=-m_{\text {cat }}\left(-2 q_{7}-2 \vartheta_{7}\right)$

$\alpha_{77}=\frac{\dot{V}_{s} p_{t o t}}{R T}$

Appendix F-Coefficients used in matrix equation for derivation of the $G$ ASO FRFs

The coefficients $\gamma_{i l}$ are in correlation with coefficients $\alpha_{i l}$, as follows

$\gamma_{i l}=\operatorname{Re}\left(\alpha_{i l}\right)$ for $i, l=1, \ldots, 5$,

$\gamma_{7 i}=\operatorname{Re}\left(\alpha_{7 i}\right)$ for $i=1, \ldots, 5$,

$\gamma_{66}=\operatorname{Re}\left(\alpha_{66}\right)$

$\gamma_{6 i}=\alpha_{6 i}$ for $i=1, \ldots, 7 \neq 6$

$\gamma_{i 6}=\alpha_{i 6}$ for $i=1, \ldots, 7 \neq 6$ 
$\gamma_{i 7}=\alpha_{i 7}$ for $i=1, \ldots, 5$

The auxiliary functions are defined as follows:

$$
\begin{aligned}
\Gamma_{i x}=-\frac{\dot{V}_{s}}{\dot{V}_{0, s}}[ & \left.G_{i, x}^{(1)}(\omega) G_{7, x}^{(1)}(-\omega)+G_{i, x}^{(1)}(-\omega) G_{7, x}^{(1)}(\omega)\right] \\
& +\frac{R T}{p_{i, s} \dot{V}_{0, s}} m_{c a t}\left[\sum _ { l = 1 } ^ { 6 } \sum _ { k = l } ^ { 6 } ( v _ { i , 1 } Q _ { l k } + v _ { i , 2 } U _ { l k } + v _ { i , 3 } S _ { l k } ) \left(G_{l, x}^{(1)}(\omega) G_{k, x}^{(1)}(-\omega)\right.\right. \\
& \left.\left.+G_{l, x}^{(1)}(-\omega) G_{k, x}^{(1)}(\omega)\right)\right], i=1, \ldots, 5 ; x=1, \ldots 4
\end{aligned}
$$

$$
\begin{aligned}
\Gamma_{6 x}=\left[-E_{2}\right] & \left(G_{2, x}^{(1)}(\omega) G_{6, x}^{(1)}(-\omega)+G_{2, x}^{(1)}(-\omega) G_{6, x}^{(1)}(\omega)\right) \\
& +\left[-E_{1}\right]\left(G_{3, x}^{(1)}(\omega) G_{6, x}^{(1)}(-\omega)+G_{3, x}^{(1)}(-\omega) G_{6, x}^{(1)}(\omega)\right) \\
& +\left[-E_{3}\right]\left(G_{4, x}^{(1)}(\omega) G_{6, x}^{(1)}(-\omega)+G_{4, x}^{(1)}(-\omega) G_{6, x}^{(1)}(\omega)\right) \\
& +\left[-E_{4}\right]\left(G_{5, x}^{(1)}(\omega) G_{6, x}^{(1)}(-\omega)+G_{5, x}^{(1)}(-\omega) G_{6, x}^{(1)}(\omega)\right), x=1, \ldots 4
\end{aligned}
$$

$$
\begin{gathered}
\Gamma_{7 x}=m_{c a t} \sum_{i}^{5}\left[\sum _ { l = 1 } ^ { 6 } \sum _ { k = l } ^ { 6 } ( v _ { i , 1 } Q _ { l k } + v _ { i , 2 } U _ { l k } + v _ { i , 3 } S _ { l k } ) \left(G_{l, x}^{(1)}(\omega) G_{k, x}^{(1)}(-\omega)\right.\right. \\
\left.\left.+G_{l, x}^{(1)}(-\omega) G_{k, x}^{(1)}(\omega)\right)\right], x=1, \ldots 4
\end{gathered}
$$




\section{Appendix G - Optimization of steady-state}

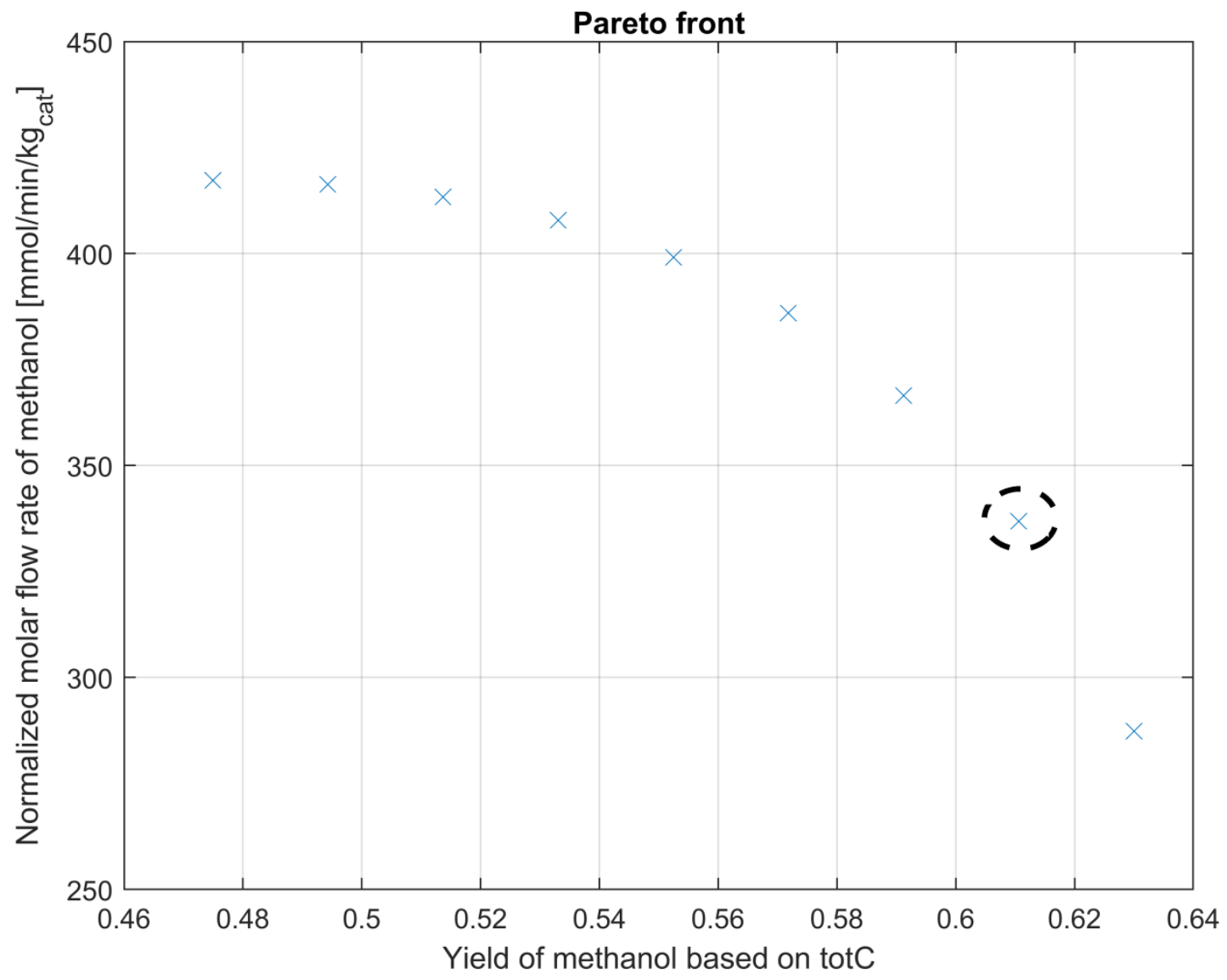

Figure G.1. Pareto front for optimal steady-state with respect of two objective functions (normalized outlet molar flow-rate of methanol $\left(\mathrm{mmol} / \mathrm{min} / \mathrm{kg}_{\mathrm{cat}}\right)$ and yield of methanol based on total carbon $(\%))$ 


\section{References}

Armstrong C. D., Teixeira, A.R., (2020). Advances in dynamically controlled catalytic reaction engineering, Reaction, Chemistry \& Engineering, DOI: 10.1039/d0re00330a

Bailey, J.E. (1973). Periodic operation of chemical reactors: A review. Chemical Engineering Communications, 1, pp. 111-124.

Chanchlani, K.G., Hudgins, R.R., Silveston, P.L., (1992) Activation of Cu/ZnO methanol catalysts by periodic compositions switching, Progress in Catalysis, pp. 331-333

Chanchlani, K.G., Hugins, R.R., Silveston, P.L., (1994) Methanol Synthesis Under periodic Operation: An Experimental Investigation, The Canadian Journal of Chemical Engineering, 72, pp. 657-671

Chen, C.C., Hwang, C. and Yang R.Y. (1994). Optimal periodic forcing of nonlinear chemical processes for performance improvements. The Canadian Journal of Chemical Engineering, 71, pp. 672-682.

Currie, R., Nikolić, D., Petkovska, M., Simakov, D., (2018), CO2 Conversion Enhancement in a Periodically Operated Sabatier Reactor: Nonlinear Frequency Response Analysis and Simulation-based Study, Israel Journal of Chemistry, 58(6), pp. 762-775

Douglas, J.M. and Rippin, D.W.T. (1966). Unsteady state process operation. Chemical Engineering Science, 21, pp. 305-315.

Douglas, J.M. (1967). Periodic reactor operation. Industrial and Engineering Chemistry Process Design and Development, 6, pp. 43-48.

Douglas, J.M. (1972). Process Dynamics and Control. New Jersey: Prentice-Hall, Englewood Cliffs.

Felischak, M., Kaps, L., Hamel, C., Nikolic, D., Petkovska, M., Seidel-Morgenstern, A. (2021). Analysis and experimental demonstration of forced periodic operation of an adiabatic stirred tank reactor: Simultaneous modulation of inlet concentration and total flow-rate, Chemical Engineering Journal, 410, 128197, https://doi.org/10.1016/j.cej.2020.128197.

Felischak, M. (2020), Enhanced reactor performance by dynamic operation: Application of inherent and forced periodic behaviour, $\mathrm{PhD}$ Thesis, Faculty of Process and Systems Engineering, Otto-von-Guericke University.

Fiedler, E., Grossmann, G., Kersebohm, D.B., Weiss, G., Witte, C., (2000). Methanol. WileyVCH Verlag GmbH \& Co, KGaA. 
Graaf, G.H., Stamhuis, E.J., Beenackers, A.A.C.M., (1988). Kinetics of low-pressure methanol synthesis, Chemical Engineering Science, 43,12,p.3185-3195.

Haimes Y.V., Lasdon L.S., Wismer D.A., (1971). On a bicriterion formation of the problems of integrated system identification and system optimization. IEEE Transactions on Systems, Man and Cybernetics. https://doi.org/10.1109/TSMC.1971.4308298.

Larsen H. H., Sonderberg Petersen, L., (2013). DTU International Energy Report 2013: Energy Storage Options for Future Sustainable Energy Systems. Technical University Denmark.

Marković, A., Seidel-Morgenstern, A. and Petkovska, M. (2008). Evaluation of the potential of periodically operated reactors based on the second order frequency response functions. Chemical Engineering Research and Design, 86, pp. 682-691.

Martin, M., (2016) Methodology for solar and wind energy chemical storage facilities design under uncertainty: methanol production from $\mathrm{CO}_{2}$ and hydrogen. Comput. Chem. Eng. 92, 4354.

Nikolić-Paunić, D. and Petkovska, M. (2013). Evaluation of periodic processes with two modulated inputs based on nonlinear frequency response analysis. Case study: CSTR with modulation of the inlet concentration and flow-rate. Chemical Engineering Science, 104, pp. 208-219.

Nikolić, D., Seidel-Morgenstern, A. and Petkovska, M. (2014a). Nonlinear frequency response analysis of forced periodic operations of non-isothermal CSTR with single input modulations. Part I: Modulation of inlet concentration or flow-rate. Chemical Engineering Science, 117, pp. 71-84.

Nikolić, D, Seidel-Morgenstern, A. and Petkovska, M. (2014b). Nonlinear frequency response analysis of forced periodic operations of non-isothermal CSTR with single input modulations. Part II: Modulation of inlet temperature or temperature of the heating/cooling fluid. Chemical Engineering Science, 117, pp. 31-44.

Nikolić, D., Seidel-Morgenstern, A. and Petkovska, M. (2015). Nonlinear frequency response analysis of forced periodic operation of non-isothermal CSTR with simultaneous modulation of inlet concentration and inlet temperature. Chemical Engineering Science, 137, pp. 40-58.

Nikolić, D., (2016) Forced Periodically Operated Chemical Reactors- Evaluation and Analysis by the Nonlinear Frequency Response Method, PhD Thesis, Faculty of Technology and Metallurgy, University of Belgrade. 
Nikolić, D., Seidel-Morgenstern, A., Petkovska, M. (2016a). Periodic operation with modulation of inlet concentration and flow-rate Part I Non-isothermal continuous stirred-tank reactor, Chemical Engineering and Technology, Volume 39, Issue 11, p. 2020-2028

Nikolić, D., Felischak, M., Seidel-Morgenstern, A., Petkovska, M. (2016b), Periodic operation with modulation of inlet concentration and flow-rate Part II Adiabatic continuous stirred-tank reactor, Chemical Engineering and Technology, Volume 39, Issue 11, p. 2126-2134

Nikolić, D., Petkovska, M. (2016), Evaluation of Performance of Periodically Operated Reactors for Single Input Modulations of General Waveforms, Chemie Ingenieur Technik, Volume 88, Issue 11, p. 1715-1722

Nikolić, D., Seidel-Morgenstern, A., Petkovska, M., (2020), Nonlinear frequency response analysis of forced periodic operations with simultaneous modulation of two general wavefrom inputs with application on adiabatic CSTR with square-wave modulations, Chemical Engineering Science, 226

Olah, G.A., (2004). After oil and gas: methanol economy. Catal. Lett. 93 (1), 1-2.

Olah, G.A., (2005). Beyond oil and gas: methanol economy. Angew. Chem. Int. Ed. 44 (18), 2636-2639.

Ovesen, C.V., Clausen, B.S., Schiotz, J., Stoltze, P., Topsoe, H., Norskov, J. K., (1997). Kinetic Implications of Dynamical Changes in Catalyst Morphology during Methanol Synthesis over $\mathrm{Cu} / \mathrm{ZnO}$ Catalysts, Journal of Catalysis, 168, 2, p. 133-142.

Parulekar, S. J. (2003). Systematic performance analysis of continuous processes subject to multiple input cycling. Chemical Engineering Science 58, pp. 5173-5194

Petkovska, M., Nikolić, D., Marković, A. and Seidel-Morgenstern, A. (2010). Fast evaluation of periodic operation of a heterogeneous reactor based on nonlinear frequency response analysis. Chemical Engineering Science, 65, pp. 3632-3637.

Petkovska, M. and Seidel-Morgenstern, A. (2013). Evaluation of periodic processes. In: Silveston, R.R. and Hudgins, R.R., ed., Periodic Operation of Reactors, Amsterdam: Elsevier, pp. 387-413.

Petkovska, M., Nikolić, D., Seidel-Morgenstern, A., (2018), Nonlinear Frequency Response Method for Evaluating Forced Periodic Operations of Chemical Reactors, Israel Journal of Chemistry 58(6), pp. 1-20.

Raeuchle, K., Plass, L., Wernicke, H. J., Bertau, M., (2016). Methanol for renewable energy storage and utilization. Energy Technol. 4(1), 193-200. 
Renken, A. (1972). The use of periodic operation to improve the performance of continuous stirred tank reactors. Chemical Engineering Science, 27, pp. 1925-1932.

Schadlich, K., Hoffmann, U. and Hofmann, H. (1983). Periodical operation of chemical processes and evaluation of conversion improvements. Chemical Engineering Science, 38, pp. $1375-1384$.

Seidel., C., Jorke, A., Vollbrecht, B., Seidel-Morgenstern, A., Kienle, A., (2018). Kinetic modeling of methanol synthesis from renewable resources, Chemical Engineering Science, 175, $130-138$

Seidel., C., Jorke, A., Vollbrecht, B., Seidel-Morgenstern, A., Kienle, A., (2020), Corrigendum to Kinetic Modelling of Methanol Synthesis from Renewable Resources, (Chem. Eng. Sci. 175 (2018), 130-138), Chemical Engineering Science 223, 115724.

Silveston, P.L. (1987). Periodic operation of chemical reactors-a review of the experimental literature. Sadhana, 10, pp. 217-246.

Silveston, P., Hudgins, R. and Renken, A. (1995). Periodic operation of catalytic reactors introduction and overview, Catalysis Today, 25 pp. 91-112.

Silveston, P.L. (1998). Composition Modulation of Catalytic Reactors. Amsterdam: Gordon and Breach Science Publishers.

Silveston, P.L. and Hudgins, R.R. (editors) (2013). Periodic Operation of Reactors, Amsterdam: Elsevier

Slatboom Y., Bos M.J., Pieper J., Vrieswijk V., Likozar B., Kersten S.R.A., Brilman D.W.F., (2020). Critical assessment of steady-state kinetic models for the synthesis of methanol over an industrial $\mathrm{Cu} / \mathrm{ZnO} / \mathrm{Al} 2 \mathrm{O} 3$ catalyst, Chemical Engineering Journal 389, 124181.

Sterman L.E. and Ydstie B.E. (1990a). Unsteady-state multivariable analysis of periodically perturbed systems. Chemical Engineering Science, 45, pp.737-749.

Sterman, L. E. and Ydstie B. E. (1990b). The steady-state process with periodic perturbations. Chemical Engineering Science 45, pp.721-736.

Sterman L. E. and Ydstie B.E (1991). Periodic forcing of the CSTR: an Application of the Generalized П-Criterion, AIChE Journal 37, pp. 986-996.

Van Gerven, T. and Stankiewicz A., (2009). Structure, Energy, Synergy, Time - The Fundamentals of Process Intensification, Ind Eng Chem Res, 48, 5, pp.2465-2474. 
Vollbrecht B., 2007. Zur Kinetic der Methanolsynthese an einem technischen Cu/ZnO/Al2O3Katalysator. PhD thesis, Otto-von-Guericke-Universitat Magdeburg.

Volterra, V. (1959). Theory of Functionals and Integral and Integrodifferential Equations. New York: Dover.

Weiner, D.D. and Spina, J.F. (1980). Sinusoidal Analysis and Modeling of Weakly Nonlinear Circuits. New York: Van Nostrand Reinhold Company

Živković L., Vidaković-Koch T., Petkovska M., (2020a). Computer-Aided Nonlinear Frequency Response Method for Investigating the Dynamics of Chemical Engineering Systems, Processes, 8, 1354, doi;10.3390/pr8111354

Živković L., Milić V., Vidaković-Koch T., Petkovska M., (2020b). Rapid Multi-Objective Optimization of Periodically Operated Processes Based on the Computer-Aided Nonlinear Frequency Response Method, Processes, 8, 1357, doi;10.3390/pr8111357. 
Supplementary material

Forced periodic operations of a chemical reactor for methanol synthesis - the search for the best scenario based on Nonlinear Frequency Response Method.

\section{Part I Single input modulations}

Daliborka Nikolić $^{\mathrm{a}}{ }^{*}$, Carsten Seidel $^{\mathrm{b}}$, Matthias Felischak ${ }^{\mathrm{c}}$, Tamara Miličić ${ }^{\mathrm{d}}$, Achim Kienle ${ }^{\mathrm{b}, \mathrm{c}}$, Anreas Seidel-Morgenstern $^{\text {b,c }}$, Menka Petkovska $^{\mathrm{d}}$

${ }^{\text {a }}$ University of Belgrade, Institute of Chemistry, Technology and Metallurgy, Njegoševa 12, 11000 Belgrade, Serbia

${ }^{\mathrm{b}}$ Otto-von-Guericke University, Universitätspl. 2, 39106 Magdeburg, Germany

${ }^{c}$ Max-Planck Institute for Dynamics of Complex Technical Systems, Sandtorstrasse 1, 39106

Magdeburg, Germany

${ }^{\mathrm{d}}$ University of Belgrade, Faculty of Technology and Metallurgy, Department of Chemical

Engineering, Karnegijeva 4, 11000 Belgrade, Serbia 
Supplementary material- The periodic operation around the steady-state with respect to maximal $H$ ASO FRFs

Single input modulation of inlet partial pressure of $\mathrm{CO}_{2}$

Table S1 The values of input and output variables for steady-state ( $p_{t o t}=60 \mathrm{bar}$ ) with respect to maximal value of $\boldsymbol{H}$ ASO FRF $\mathrm{H}^{(2)}{ }_{1,1,1}(\omega,-\omega)$

\begin{tabular}{|c|c|c|c|c|c|c|}
\hline \multicolumn{7}{|c|}{ Inputs (steady-state) } \\
\hline \multicolumn{5}{|c|}{ Molar fraction of component, [-] } & \multicolumn{2}{|c|}{$\begin{array}{l}\text { Temperature } \\
{[K]}\end{array}$} \\
\hline$y_{0, s}\left(\mathrm{CO}_{2}\right)$ & $y_{0, s}(\mathrm{CO})$ & \multicolumn{3}{|c|}{$y_{0, s}\left(\mathrm{H}_{2}\right)$} & \multicolumn{2}{|c|}{$T[\mathrm{~K}]$} \\
\hline 0.0014 & 0.1988 & \multicolumn{3}{|c|}{0.6498} & \multicolumn{2}{|c|}{473} \\
\hline \multicolumn{7}{|c|}{ Forcing parameters for maximal improvement } \\
\hline \multicolumn{5}{|c|}{ Forcing frequency, dimesionless [-] } & \multicolumn{2}{|c|}{0.3364} \\
\hline \multicolumn{5}{|c|}{ Forcing amplitude of $\mathrm{CO}_{2}$} & \multicolumn{2}{|c|}{1} \\
\hline \multicolumn{7}{|c|}{ Ouputs (steady-state) } \\
\hline \multicolumn{2}{|c|}{$\dot{V}_{\text {out }}, \mathrm{ml} / \mathrm{min}$} & \multicolumn{5}{|c|}{6.6204} \\
\hline$y_{s}\left(\mathrm{CH}_{3} \mathrm{OH}\right)$ & $y_{s}\left(\mathrm{CO}_{2}\right)$ & $\begin{array}{c}y_{S} \\
(\mathrm{CO})\end{array}$ & $y_{s}\left(\mathrm{H}_{2}\right)$ & $y_{s}\left(\mathrm{H}_{2} \mathrm{O}\right)$ & $\begin{array}{c}y_{S} \\
\left(\mathrm{~N}_{2}\right)\end{array}$ & $y_{\text {tot }, s}$ \\
\hline 0.0234 & 0.0014 & 0.1847 & 0.6333 & $5.89 * 10^{-5}$ & 0.1570 & 1 \\
\hline \multicolumn{2}{|c|}{$\dot{n}_{C H_{3} O H, S}^{\text {norm }},\left[\mathrm{mmol} / \mathrm{min} / \mathrm{kg}_{\mathrm{cat}}\right]$} & \multicolumn{5}{|c|}{55.95} \\
\hline \multicolumn{2}{|c|}{$\begin{array}{c}\text { Yield of methanol based on } \\
\text { total C, } \%\end{array}$} & \multicolumn{5}{|c|}{11.19} \\
\hline \multicolumn{2}{|c|}{$\begin{array}{l}\text { Yield of methanol based on } \mathrm{H}_{2}, \\
\%\end{array}$} & \multicolumn{5}{|c|}{6.89} \\
\hline \multicolumn{7}{|c|}{ Ouputs for periodic modulation with maximal improvement } \\
\hline \multicolumn{2}{|c|}{$\mathrm{H}^{(2)}{ }_{1,1,1}(\omega,-\omega)^{\max }$} & \multicolumn{5}{|c|}{0.0046} \\
\hline \multicolumn{2}{|c|}{$\left(\dot{n}_{\mathrm{CH}_{3} \mathrm{OH}}^{\text {norm }}\right)_{\text {mean }},\left[\mathrm{mmol} / \mathrm{min} / \mathrm{kg}_{\text {cat }}\right]$} & \multicolumn{5}{|c|}{60.09} \\
\hline \multicolumn{2}{|c|}{$\begin{array}{l}\text { Yield of methanol based on } \\
\text { total } C, \%\end{array}$} & \multicolumn{5}{|c|}{11.21} \\
\hline \multicolumn{2}{|c|}{$\begin{array}{l}\text { Yield of methanol based on } \mathrm{H}_{2} \text {, } \\
\%\end{array}$} & \multicolumn{5}{|c|}{6.91} \\
\hline \multicolumn{2}{|c|}{$\begin{array}{l}\text { Maximal increase of outlet } \\
\text { molar flow-rate of methanol, } \\
\text { yield of methanol based on tot } \\
\text { C or based on } \mathrm{H}_{2}, \%\end{array}$} & \multicolumn{5}{|c|}{0.23} \\
\hline
\end{tabular}




\section{Single input modulation of inlet partial pressure of $\mathrm{CO}$}

Table S2 The values of input and output variables for steady-state ( $p_{t o t}=60 \mathrm{bar}$ ) with respect to maximal value of $\boldsymbol{H}$ ASO FRF $\mathrm{H}_{1,2,2}^{(2)}(\omega,-\omega)$

\begin{tabular}{|c|c|c|c|c|c|c|}
\hline \multicolumn{7}{|c|}{ Inputs (steady-state) } \\
\hline$y_{0, s}\left(\mathrm{CO}_{2}\right)$ & $y_{0, s}(\mathrm{CO})$ & \multicolumn{3}{|c|}{$y_{0, s}\left(\mathrm{H}_{2}\right)$} & \multicolumn{2}{|c|}{$T[\mathrm{~K}]$} \\
\hline 0.0814 & 0.0482 & \multicolumn{3}{|c|}{0.7204} & \multicolumn{2}{|c|}{473} \\
\hline \multicolumn{7}{|c|}{ Forcing parameters for maximal improvement } \\
\hline \multicolumn{5}{|c|}{ Forcing frequency, dimesionless [-] } & \multicolumn{2}{|c|}{0.2889} \\
\hline \multicolumn{5}{|c|}{ Forcing amplitude of $\mathrm{CO}$} & \multicolumn{2}{|c|}{1} \\
\hline \multicolumn{7}{|c|}{ Ouputs (steady-state) } \\
\hline \multicolumn{2}{|c|}{$\dot{V}_{\text {out }}, \mathrm{ml} / \mathrm{min}$} & \multicolumn{5}{|c|}{6.3696} \\
\hline$y_{s}\left(\mathrm{CH}_{3} \mathrm{OH}\right)$ & $y_{s}\left(\mathrm{CO}_{2}\right)$ & $y_{s}(\mathrm{CO})$ & $y_{s}\left(\mathrm{H}_{2}\right)$ & $y_{s}\left(\mathrm{H}_{2} \mathrm{O}\right)$ & $y_{s}\left(\mathrm{~N}_{2}\right)$ & $y_{\text {tot }, \mathrm{s}}$ \\
\hline 0.0416 & 0.0734 & 0.0253 & 0.6824 & 0.0147 & 0.1625 & 1 \\
\hline \multicolumn{2}{|c|}{$\dot{n}_{\mathrm{CH}}^{\text {norm } \mathrm{OH}, \mathrm{S}},\left[\mathrm{mmol} / \mathrm{min} / \mathrm{kg}_{\mathrm{cat}}\right]$} & \multicolumn{5}{|c|}{102.82} \\
\hline \multicolumn{2}{|c|}{$\begin{array}{l}\text { Yield of methanol based on } \\
\text { tot } C, \%\end{array}$} & \multicolumn{5}{|c|}{29.64} \\
\hline \multicolumn{2}{|c|}{$\begin{array}{l}\text { Yield of methanol based on } \\
\qquad \mathrm{H}_{2}, \%\end{array}$} & \multicolumn{5}{|c|}{10.66} \\
\hline \multicolumn{7}{|c|}{ Ouputs for periodic modulation with maximal improvement } \\
\hline \multicolumn{2}{|c|}{$\mathrm{H}^{(2)}{ }_{1,2,2}(\omega,-\omega)^{\max }$} & \multicolumn{5}{|c|}{0.0989} \\
\hline \multicolumn{2}{|c|}{$\begin{array}{c}\left(\dot{n}_{\mathrm{CH}_{3} \mathrm{OH}}^{\text {norm }}\right)_{\text {mean }} \\
{\left[\mathrm{mmol} / \mathrm{min} / \mathrm{kg}_{\text {cat }}\right]}\end{array}$} & \multicolumn{5}{|c|}{107.90} \\
\hline \multicolumn{2}{|c|}{$\begin{array}{l}\text { Yield of methanol based on } \\
\text { tot } C, \%\end{array}$} & \multicolumn{5}{|c|}{31.10} \\
\hline \multicolumn{2}{|c|}{$\begin{array}{l}\text { Yield of methanol based on } \\
\qquad \mathrm{H}_{2}, \%\end{array}$} & \multicolumn{5}{|c|}{11.19} \\
\hline \multicolumn{2}{|c|}{$\begin{array}{l}\text { Maximal increase of outlet } \\
\text { molar flow-rate of methanol, } \\
\text { yield of methanol based on } \\
\text { total } \mathrm{C} \text { or based on } \mathrm{H}_{2}, \%\end{array}$} & \multicolumn{5}{|c|}{4.95} \\
\hline
\end{tabular}




\section{Single input modulation of inlet partial pressure of $\mathbf{H}_{\mathbf{2}}$}

Table S3 The values of input and output variables for steady-state ( $p_{t o t}=60$ bar) with respect to maximal value of $\boldsymbol{H}$ ASO FRF $\mathrm{H}_{1,3,3}^{(2)}(\omega,-\omega)$

\begin{tabular}{|c|c|c|c|c|c|c|}
\hline \multicolumn{7}{|c|}{ Inputs (steady-state) } \\
\hline$y_{0, s}\left(\mathrm{CO}_{2}\right)$ & $y_{0, s}(\mathrm{CO})$ & \multicolumn{3}{|c|}{$y_{0, s}\left(\mathrm{H}_{2}\right)$} & \multicolumn{2}{|c|}{$T[\mathrm{~K}]$} \\
\hline 0.0250 & 0.3250 & \multicolumn{3}{|c|}{0.5000} & \multicolumn{2}{|c|}{533} \\
\hline \multicolumn{7}{|c|}{ Forcing parameters for maximal improvement } \\
\hline \multicolumn{5}{|c|}{ Forcing frequency, dimesionless [-] } & \multicolumn{2}{|c|}{0.4354} \\
\hline \multicolumn{5}{|c|}{ Forcing amplitude of $\mathrm{H}_{2}$} & \multicolumn{2}{|c|}{0.3000} \\
\hline \multicolumn{7}{|c|}{ Ouputs (steady-state } \\
\hline \multicolumn{2}{|c|}{$\dot{V}_{\text {out }}, \mathrm{ml} / \mathrm{min}$} & \multicolumn{5}{|c|}{6.2826} \\
\hline$y_{s}\left(\mathrm{CH}_{3} \mathrm{OH}\right)$ & $y_{s}\left(\mathrm{CO}_{2}\right)$ & $y_{s}(\mathrm{CO})$ & $y_{s}\left(\mathrm{H}_{2}\right)$ & $y_{s}\left(\mathrm{H}_{2} \mathrm{O}\right)$ & $y_{s}\left(\mathrm{~N}_{2}\right)$ & $y_{\text {tot }, s}$ \\
\hline 0.1215 & 0.0304 & 0.2831 & 0.3778 & $6.5610^{-4}$ & 0.1865 & 1 \\
\hline \multicolumn{2}{|c|}{$\dot{n}_{\mathrm{CH}_{3} \mathrm{OH}, \mathrm{S}}^{\text {norm }},\left[\mathrm{mmol} / \mathrm{min} / \mathrm{kg}_{\mathrm{cat}}\right]$} & \multicolumn{5}{|c|}{261.72} \\
\hline \multicolumn{2}{|c|}{$\begin{array}{l}\text { Yield of methanol based on } \\
\text { total C, } \%\end{array}$} & \multicolumn{5}{|c|}{27.93} \\
\hline \multicolumn{2}{|c|}{$\begin{array}{l}\text { Yield of methanol based on } \\
\qquad \mathrm{H}_{2}, \%\end{array}$} & \multicolumn{5}{|c|}{39.11} \\
\hline \multicolumn{7}{|c|}{ Ouputs for periodic modulation with maximal improvement } \\
\hline \multicolumn{2}{|c|}{$\mathrm{H}_{1,3,3}^{(2)}(\omega,-\omega)^{\max }$} & \multicolumn{5}{|c|}{0.1508} \\
\hline \multicolumn{2}{|c|}{$\begin{array}{c}\left(\dot{n}_{\mathrm{CH}_{3} \mathrm{OH}}^{\mathrm{norm}}\right)_{\text {mean }} \\
{\left[\mathrm{mmol} / \mathrm{min} / \mathrm{kg}_{\text {cat }}\right]}\end{array}$} & \multicolumn{5}{|c|}{263.50} \\
\hline \multicolumn{2}{|c|}{$\begin{array}{c}\text { Yield of methanol based on } \\
\text { total } \mathrm{C}, \%\end{array}$} & \multicolumn{5}{|c|}{28.12} \\
\hline \multicolumn{2}{|c|}{$\begin{array}{l}\text { Yield of methanol based on } \\
\qquad \mathrm{H}_{2}, \%\end{array}$} & \multicolumn{5}{|c|}{39.37} \\
\hline \multicolumn{2}{|c|}{$\begin{array}{l}\text { Maximal increase of outlet } \\
\text { molar flow-rate of methanol, } \\
\text { yield of methanol based on } \\
\text { total } \mathrm{C} \text { or based on } \mathrm{H}_{2}, \%\end{array}$} & \multicolumn{5}{|c|}{0.68} \\
\hline
\end{tabular}




\section{Single input modulation of inlet volumetric flow-rate}

Table S4 The values of input and output variables for steady-state ( $p_{t o t}=60 \mathrm{bar}$ ) with respect to maximal value of $\boldsymbol{H}$ ASO FRF $\mathrm{H}_{1,4,4}^{(2)}(\omega,-\omega)$

\begin{tabular}{|c|c|c|c|c|c|c|}
\hline \multicolumn{7}{|c|}{ Inputs (steady-state) } \\
\hline$y_{0, s}\left(\mathrm{CO}_{2}\right)$ & $y_{0, s}(\mathrm{CO})$ & \multicolumn{3}{|c|}{$y_{0, s}\left(\mathrm{H}_{2}\right)$} & \multicolumn{2}{|c|}{$T[\mathrm{~K}]$} \\
\hline $3.516610^{-4}$ & 0.0096 & \multicolumn{3}{|c|}{0.8400} & \multicolumn{2}{|c|}{473} \\
\hline \multicolumn{7}{|c|}{ Forcing parameters for maximal improvement } \\
\hline \multicolumn{5}{|c|}{ Forcing frequency, dimesionless [-] } & \multicolumn{2}{|c|}{13.6903} \\
\hline \multicolumn{5}{|c|}{ Forcing amplitude of inlet volumetric flow-rate } & \multicolumn{2}{|c|}{1} \\
\hline \multicolumn{7}{|c|}{ Ouputs (steady-state) } \\
\hline \multicolumn{2}{|c|}{$\dot{V}_{\text {out }}, \mathrm{ml} / \mathrm{min}$} & \multicolumn{5}{|c|}{8.844} \\
\hline$y_{s}\left(\mathrm{CH}_{3} \mathrm{OH}\right)$ & $y_{s}\left(\mathrm{CO}_{2}\right)$ & $y_{s}(\mathrm{CO})$ & $y_{s}\left(\mathrm{H}_{2}\right)$ & $y_{s}\left(\mathrm{H}_{2} \mathrm{O}\right)$ & $y_{s}\left(\mathrm{~N}_{2}\right)$ & $y_{\text {tot }, s}$ \\
\hline 0.0029 & $1.770710^{-4}$ & 0.0069 & 0.8389 & $1.7663 * 10^{-4}$ & 0.1509 & 1 \\
\hline \multicolumn{2}{|c|}{$\dot{n}_{\mathrm{CH}_{3} \mathrm{OH}, \mathrm{s}}^{\text {norm }},\left[\mathrm{mmol} / \mathrm{min} / \mathrm{kg}_{\mathrm{cat}}\right]$} & \multicolumn{5}{|c|}{7.69} \\
\hline \multicolumn{2}{|c|}{$\begin{array}{l}\text { Yield of methanol based on } \\
\text { total } \mathrm{C}, \%\end{array}$} & \multicolumn{5}{|c|}{28.89} \\
\hline \multicolumn{2}{|c|}{$\begin{array}{l}\text { Yield of methanol based on } \\
\qquad \mathrm{H}_{2}, \%\end{array}$} & \multicolumn{5}{|c|}{0.68} \\
\hline \multicolumn{7}{|c|}{ Ouputs for periodic modulation with maximal improvement } \\
\hline \multicolumn{2}{|c|}{$\mathrm{H}^{(2)}{ }_{1,4,4}(\omega,-\omega)^{\max }$} & \multicolumn{5}{|c|}{0.0023} \\
\hline \multicolumn{2}{|c|}{$\begin{array}{c}\left(\dot{n}_{\mathrm{CH}_{3} \mathrm{OH}}^{\text {norm }}\right)_{\text {mean }}, \\
{\left[\mathrm{mmol} / \mathrm{min} / \mathrm{kg}_{\text {cat }}\right]}\end{array}$} & \multicolumn{5}{|c|}{7.70} \\
\hline \multicolumn{2}{|c|}{$\begin{array}{l}\text { Yield of methanol based on } \\
\text { total C, } \%\end{array}$} & \multicolumn{5}{|c|}{28.92} \\
\hline \multicolumn{2}{|c|}{$\begin{array}{l}\text { Yield of methanol based on } \\
\qquad \mathrm{H}_{2}, \%\end{array}$} & \multicolumn{5}{|c|}{0.69} \\
\hline \multicolumn{2}{|c|}{$\begin{array}{l}\text { Maximal increase of outlet } \\
\text { molar flow-rate of methanol, } \\
\text { yield of methanol based } \\
\text { ontotal C or based on } \mathrm{H}_{2}, \%\end{array}$} & \multicolumn{5}{|c|}{0.12} \\
\hline
\end{tabular}

